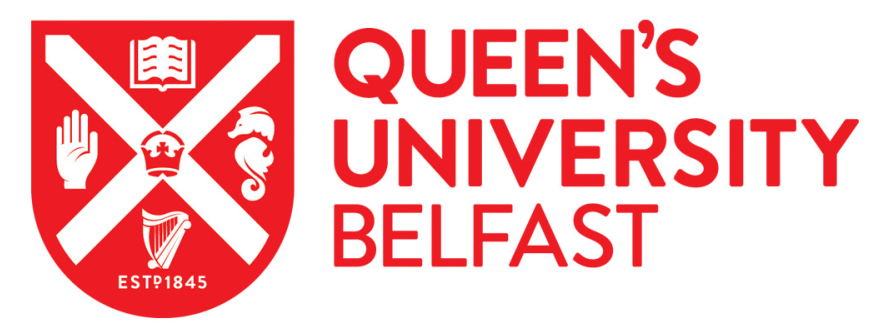

\title{
Designing dimeric lanthanide(III)-containing ionic liquids
}

McCourt, É., Esien, K., Zhenyu, L., Felton, S., \& Nockemann, P. (2023). Designing dimeric lanthanide(III)containing ionic liquids. Angewandte Chemie International Edition, 62(7), [e201809334].

https://doi.org/10.1002/anie.201809334

\section{Published in:}

Angewandte Chemie International Edition

\section{Document Version:}

Peer reviewed version

Queen's University Belfast - Research Portal:

Link to publication record in Queen's University Belfast Research Portal

\section{Publisher rights}

Copyright 2018 Wiley-VCHGmbH. This work is made available online in accordance with the publisher's policies. Please refer to any applicable terms of use of the publisher.

\section{General rights}

Copyright for the publications made accessible via the Queen's University Belfast Research Portal is retained by the author(s) and / or other copyright owners and it is a condition of accessing these publications that users recognise and abide by the legal requirements associated with these rights.

Take down policy

The Research Portal is Queen's institutional repository that provides access to Queen's research output. Every effort has been made to ensure that content in the Research Portal does not infringe any person's rights, or applicable UK laws. If you discover content in the Research Portal that you believe breaches copyright or violates any law, please contact openaccess@qub.ac.uk. 


\title{
Designing Dimeric Lanthanide(III)-Containing lonic liquids
}

\author{
Éadaoin McCourt, ${ }^{[a]}$ Kane Esien, ${ }^{[b]}$ Li Zhenyu, ${ }^{[a]}$ Solveig Felton, ${ }^{*[b]}$ and Peter Nockemann*[a]
}

\begin{abstract}
Herein, we report on the preparation of liquid dimeric lanthanide(III)-containing compounds. Starting from the design of dimeric solids, we demonstrate that by tuning of anion and cation structures we can lower the melting points below room temperature, whilst maintaining the dimeric structure. Magnetic measurements could establish the spin-spin interactions of the neighboring lanthanide(III) ions in the liquid state at low temperatures, and matched the interactions of the analogous crystalline solid compounds.
\end{abstract}

Lanthanide-containing soft materials are a fascinating class of materials with intrinsic luminescent ${ }^{[1]}$ and magnetic properties. ${ }^{[2]}$ The potential of lanthanides to generate significant magnetic anisotropy has led to di- or polynuclear lanthanide (III) complexes receiving great attention. ${ }^{[3-6]}$ Polymetallic assemblies can exhibit cooperative metalmetal interactions affecting their magnetic, electronic and photophysical properties. ${ }^{[7]}$

Ionic liquids (ILs) by definition are salts which have melting points below $100{ }^{\circ} \mathrm{C}$ or commonly at room temperature (RTILs). ${ }^{[8]}$ Properties such as low-volatility, high conductivity, extensive anion and cation tunability, wide liquid range and high thermal stability are found for these compounds. ${ }^{[9-12]}$ The first ionic liquid reported to show a strong response to a magnet was 1-butyl-3-methylimidazolium tetrachloroferrate, $\left[\mathrm{C}_{4} \mathrm{Mim}\right]\left[\mathrm{FeCl}_{4}\right] .{ }^{[13,14]}$

Since then, many magneto-active metal-containing ionic liquids have been reported ${ }^{[15]}$ in which the magnetic functionality is incorporated into the anion structure; e.g. $\mathrm{Mn}^{11} \mathrm{Cl}_{4}{ }^{2-}, \mathrm{Co}(\mathrm{NCS})_{4}{ }^{2-}{ }^{[16-18]}$ Magnetic measurements carried out on $\left[\mathrm{C}_{2} \mathrm{Mim}\right]\left[\mathrm{FeCl}_{4}\right]$ have also shown long range antiferromagnetic ordering at low temperatures. ${ }^{[19]}$

We have previously reported on the first liquid complexes containing lanthanide anions with thiocyanate ligands. ${ }^{[20]}$ The magnetic and luminescent properties of $\left[\mathrm{C}_{6} \mathrm{Mim}\right]_{5-x}\left[\mathrm{Dy}(\mathrm{SCN})_{8-\mathrm{x}}\left(\mathrm{H}_{2} \mathrm{O}\right)_{x}\right]$ where subsequently explored by Mallick et al. ${ }^{[2]}$ Single-ion magnetic behavior at low temperature has been reported for the Dy-containing

[a] E, McCourt, L, Zhenyu and Dr, P, Nockemann

The Quill Research Centre,

The School of Chemistry and Chemical Engineering,

Queen's University of Belfast, Belfast, BT9 5AG, United Kingdom

E-mail: p.nockemann@qub.ac.uk

[b] Dr, K, Esien and Dr, S, Felton*

Centre for Nanostructured Media,

School of Mathematics and Physics,

Queen's University of Belfast, Belfast, BT7 1NN, United Kingdom

E-mail: s.felton@qub.ac.uk

Supporting information for this article is given via a link at the end of the document.
IL $\left.\left[\mathrm{Dy}\left(\mathrm{R}-\mathrm{Im}-\mathrm{CH}_{2} \mathrm{COO}\right)_{3}\left(\mathrm{H}_{2} \mathrm{O}\right)\right)_{2}\right]\left[\left(\mathrm{PF}_{6}\right)_{3} \cdot 2 \mathrm{H}_{2} \mathrm{O}\right]{ }^{[21]}$ In this case the intrinsic magnetic functionality was incorporated into the cation structure. Recently, we investigated the physical and magnetic properties of the series $\left[\mathrm{P}_{666}\right.$ 14 $\left._{14}\right]\left[\mathrm{RECl}_{6}\right]\left(\mathrm{RE}=\right.$ Rare Earth). ${ }^{[22]}$ Further low-temperature magnetic measurements on $\left[\mathrm{P}_{666}{ }_{14}\right]\left[\mathrm{RECl}_{6}\right]$ ILs were subsequently carried out by Monson et al., ${ }^{[23]}$ reporting unusual behavior at temperatures below $50 \mathrm{~K}$, attributed to the trapping of intermediate structures during glass formation.

In this work, the magnetic and structural properties of novel crystalline, glassy and liquid lanthanide(III) containing ionic compounds, $\left[\mathrm{C}_{4} \mathrm{Mim}\right]_{2}\left[\mathrm{Ln}_{2}\left(\mathrm{CH}_{3} \mathrm{COO}\right)_{8}\right],\left[\mathrm{P}_{666} 1_{14}\right]_{2}\left[\mathrm{Ln}_{2}\left(\mathrm{CH}_{3} \mathrm{COO}\right)_{8}\right]$ and $\left[\mathrm{P}_{666} \mathrm{14}_{2}\right]_{2}\left[\mathrm{Ln}_{2}\left(\mathrm{C}_{7} \mathrm{H}_{15} \mathrm{COO}\right)_{8}\right]$ are reported ( $\mathrm{Ln}=$ lanthanide series). We demonstrate the ability to fine-tune both the anion and cation structures to realize room-temperature lanthanide-containing ionic liquids shown in Figure 1.

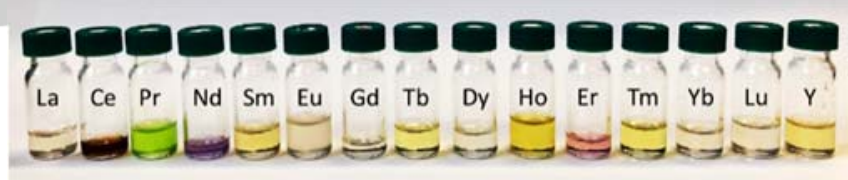

Figure 1. Room-temperature lanthanide-containing ionic liquids, $\left[\mathrm{P}_{666} 1_{14}\right]_{2}\left[\mathrm{Ln}_{2}\left(\mathrm{C}_{7} \mathrm{H}_{15} \mathrm{COO}\right)_{8}\right] \mathrm{Ln}=$ lanthanide.

This paper will focus on the dysprosium (III) containing crystalline, glassy and liquid complexes. Single-crystal X-ray diffraction provided direct evidence of the formation of a dimeric Dy..Dy complex in the solid state $\left[\mathrm{C}_{4} \mathrm{Mim}\right]_{2}\left[\mathrm{Dy}{ }_{2}\left(\mathrm{CH}_{3} \mathrm{COO}\right)_{8}\right]$ Figure 2.

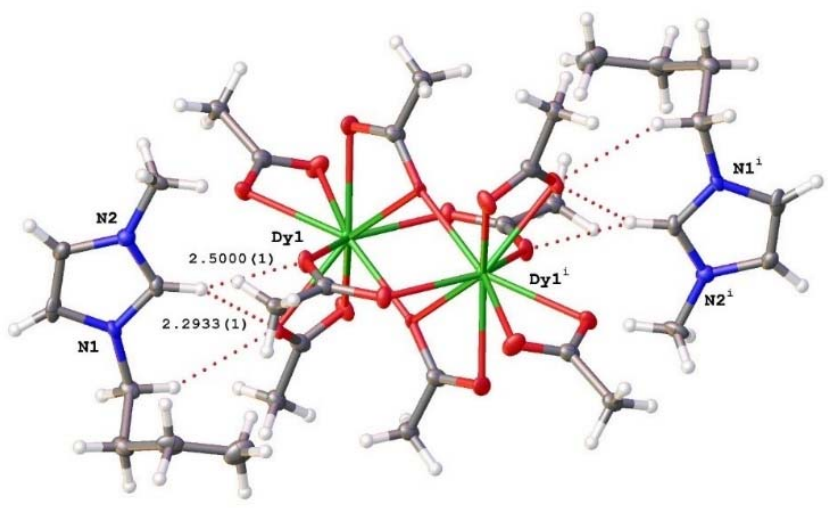

Figure 2. Crystal structure of the dimeric $\left[\mathrm{C}_{4} \mathrm{Mim}\right]_{2}\left[\mathrm{Dy}_{2}\left(\mathrm{CH}_{3} \mathrm{COO}\right)_{8}\right]$.

This ultimately led to the questions (i) "Can a dimeric structure be obtained in the liquid state?" and, if so, (ii) "How can the presence of a dimer be proven in a liquid?". 
These questions are the underlying foundation of this paper and we endeavor to answer them through a combination of techniques discussed herein. In particular, SQUID (Superconducting Quantum Interference Device) magnetometry enabled us to explore the magnetic properties of these three systems bestowing insights into the magnetic behavior over a wide temperature range. Although multiple-technique approaches, including HEXS (High Energy X-ray Scattering) and EXAFS (Extended X-ray Absorption Fine Structure) to probe the speciation of metals in the liquid state have been previously reported, the methods may provide limited information and are not easily accessible. ${ }^{[24]}$ Therefore, we looked for the presence of a magnetic interaction between the neighboring dysprosium ions. Comparison between the magnetic properties of the three samples, if such an interaction is present, will allow us to infer structure in the liquid and glassy states.

The novel lanthanide(III)-containing ionic compounds, $\left[\mathrm{C}_{4} \mathrm{Mim}\right]_{2}\left[\mathrm{Ln}_{2}\left(\mathrm{CH}_{3} \mathrm{COO}\right)_{8}\right], \quad\left[\mathrm{P}_{666} 1_{14}\right]_{2}\left[\mathrm{Ln}_{2}\left(\mathrm{CH}_{3} \mathrm{COO}\right)_{8}\right] \quad$ and $\left[\mathrm{P}_{666}{ }_{14}\right]_{2}\left[\mathrm{Ln}_{2}\left(\mathrm{C}_{7} \mathrm{H}_{15} \mathrm{COO}\right)_{8}\right]$ were synthesized via addition reactions, whereby, equimolar ratios of lanthanide(III) salt (acetate or octanoate) were reacted with the ionic liquids 1-butyl-3-methylimidazolium acetate, trihexyltetra(decyl)phosphonium acetate and trihexytetra(decyl)phosphonium octanoate. By careful selection of the cation and anion components the melting points could be tuned forming the crystalline, glass and liquid lanthanide(III)-containing compounds shown in Figure 4.

By a method of slow crystallization in a Reacti-Therm, starting at $120^{\circ} \mathrm{C}$ from the molten state with a cooling rate of $-5^{\circ} \mathrm{C}$ (m.p. $=$ $118^{\circ} \mathrm{C}$ ) to $50^{\circ} \mathrm{C}$, single crystals of $\left[\mathrm{C}_{4} \mathrm{Mim}\right]_{2}\left[\mathrm{Dy}_{2}\left(\mathrm{CH}_{3} \mathrm{COO}\right)_{8}\right]$ formed. The structure presented in Figure 2, consists of a $\left[\mathrm{Dy}_{2}\left(\mathrm{CH}_{3} \mathrm{COO}\right)_{8}\right]^{2-}$ anion and two 1-butyl-3-methylimidazolium, $\left[\mathrm{C}_{4} \mathrm{Mim}\right]^{+}$counterions. Powder XRD was used to confirm that what was obtained in the single crystal was indicative of the bulk sample (Figure S1). The Dy ${ }^{\prime \prime \prime}$ ions are linked by two carboxylate ligands in a bridging bidentate $\left(\eta^{1}: \eta^{1}: \mu_{2}\right)$ fashion and two in a bridging chelating $\left(\eta^{1}: \eta^{2}: \mu_{2}\right)$ mode. Each Dy ${ }^{\prime \prime \prime}$ ion is further surrounded by two chelating carboxylates giving a total coordination number of nine. As previously discussed by Ouchi et $a l .^{\left[{ }^{[6]}\right.}$ in the bridging chelating carboxylate groups, one of the oxygen atoms is bound in a $\mu_{2}$-bridging manner to both dysprosium atoms and the second is bound directly to one dysprosium atom as shown in Figure 2. The coordination polyhedron can be described as a distorted tricapped trigonal prism with Dy - O (carboxylate) bond lengths ranging from $2.329-2.509 \AA$ and the Dy...Dy distance within the dimer is $3.8587(6) \AA$ (for Dy1) and 3.8872(6) $\AA$ (for Dy2), respectively.

As diffraction experiments are limited to the crystalline sample other spectroscopic techniques such as IR and UV-Vis were investigated, however, whilst affording some insight into the structure, the standard spectroscopic techniques did not provide hard evidence for the question (ii) (vide supra) regarding the dimeric structure in the liquid state. The carboxylate ion, $\mathrm{RCO}_{2}^{-}$, has several possible coordination modes to a metal e.g. monodentate, bidentate chelating, bidentate bridging. Analysis of the differences $(\Delta \mathrm{v})$ in the asymmetric $v_{a}\left(\mathrm{COO}^{-}\right)$and symmetric $v_{s}\left(\mathrm{COO}^{-}\right)$wavenumbers, can be used to gain insight into the coordination modes, $\left[\Delta v=v_{a}\left(\mathrm{COO}^{-}\right)\right.$ $\left.v_{s}\left(\mathrm{COO}^{-}\right)\right]^{[25]}$ From the spectra and values presented in Figure 3 and Table 1, splitting of $\mathrm{v}_{\mathrm{a}}\left(\mathrm{COO}^{-}\right)$is observed in the crystalline, glassy and liquid samples.

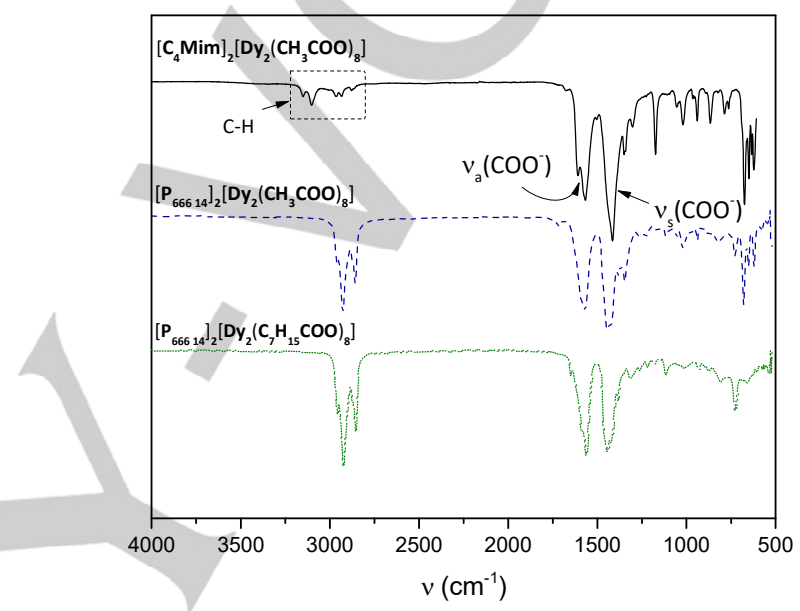

Figure 3. Infrared spectra of $\left[\mathrm{C}_{4} \mathrm{Mim}\right]_{2}\left[\mathrm{Dy}_{2}\left(\mathrm{CH}_{3} \mathrm{COO}\right)_{8}\right]$, $\left[\mathrm{P}_{666} 1_{14}\right]_{2}\left[\mathrm{Dy}{ }_{2}\left(\mathrm{CH}_{3} \mathrm{COO}\right)_{8}\right]$ and $\left[\mathrm{P}_{666} 1_{14}\right]_{2}\left[\mathrm{Dy}_{2}\left(\mathrm{C}_{7} \mathrm{H}_{15} \mathrm{COO}\right)_{8}\right]$.

This splitting leads to two separation values indicative of different bonding modes present within the sample. A mix of bidentate bridging and chelating may be deduced for the crystalline, glassy and liquid samples. UV-Vis spectroscopy of $\left[\mathrm{P}_{66614}\right]_{2}\left[\mathrm{Dy}_{2}\left(\mathrm{C}_{7} \mathrm{H}_{15} \mathrm{COO}\right)_{8}\right]$ (Figure S12) showed an absorbance spectrum characteristic of Dy'I', whilst thermal gravimetrical analysis (TGA) and differential scanning calorimetry (DSC) provided information about decomposition temperatures and phase transitions (Table 2), respectively.

Table 1: Values of $\mathbf{v}_{\mathrm{a}}\left(\mathrm{COO}^{-}\right), \mathbf{v}_{\mathrm{s}}\left(\mathrm{COO}^{-}\right)$and $\Delta_{\mathrm{v}}\left(\mathrm{COO}^{-}\right)$.

\begin{tabular}{cccc}
\hline Compound & $\begin{array}{c}\mathrm{v}_{\mathbf{a}}\left(\mathrm{COO}^{-}\right) \\
\left(\mathrm{cm}^{-1}\right)\end{array}$ & $\begin{array}{c}\mathbf{v}_{\mathrm{s}}\left(\mathrm{COO}^{-}\right) \\
\left(\mathrm{cm}^{-1}\right)\end{array}$ & $\Delta v^{[\mathrm{a}]}$ \\
\hline $\mathrm{Na}^{+} \mathrm{CH}_{3} \mathrm{COO}^{-}$ & 1578 & 1414 & $164^{[25]}$ \\
{$\left[\mathrm{C}_{4} \mathrm{Mim}\right]_{2}\left[\mathrm{Dy}_{2}\left(\mathrm{CH}_{3} \mathrm{COO}\right)_{8}\right]$} & $1598 / 1564$ & 1431 & $167 / 133$ \\
{$\left[\mathrm{P}_{666} 1_{14}\right]_{2}\left[\mathrm{Dy}_{2}\left(\mathrm{CH}_{3} \mathrm{COO}\right)_{8}\right]$} & $1578 / 1564$ & 1435 & $143 / 129$ \\
{$\left[\mathrm{P}_{666} 1_{44}\right]_{2}\left[\mathrm{Dy}_{2}\left(\mathrm{C}_{7} \mathrm{H}_{15} \mathrm{COO}\right)_{8}\right]$} & $1581 / 1558$ & 1435 & $146 / 123$ \\
\hline
\end{tabular}

[a] $\Delta_{\mathrm{v}}=\mathrm{v}_{\mathrm{a}}\left(\mathrm{COO}^{-}\right)-\mathrm{v}_{\mathrm{s}}\left(\mathrm{COO}^{-}\right)$ 
Crystal

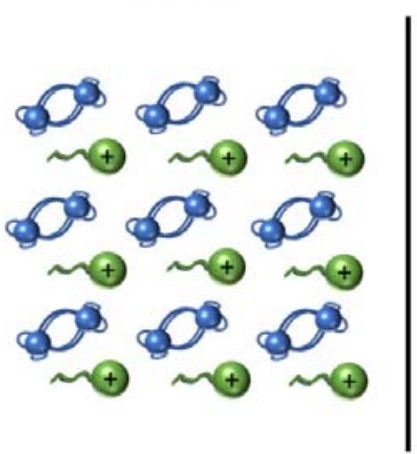

a) $\left[\mathrm{C}_{4} \mathrm{Mim}\right]_{2}\left[\mathrm{Ln}_{2}\left(\mathrm{CH}_{3} \mathrm{COO}\right)_{8}\right]$

\section{Glass}

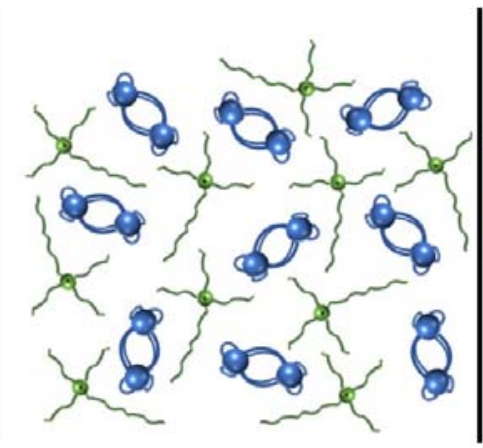

b) $\left[\mathrm{P}_{66614}\right]_{2}\left[\mathrm{Ln}_{2}\left(\mathrm{CH}_{3} \mathrm{COO}\right)_{8}\right]$

\section{Liquid}

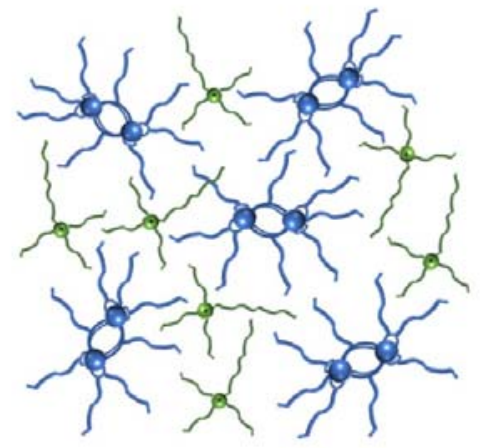

c) $\left[\mathrm{P}_{66614}\right]_{2}\left[\operatorname{Ln}_{2}\left(\mathrm{C}_{7} \mathrm{H}_{15} \mathrm{COO}\right)_{8}\right]$

Figure 4. Variations in anion and cation structure upon changing from crystalline solid to glass to liquid, with $a \rightarrow b$ changing cation from [ $\left.\mathrm{C}_{4} \mathrm{Mim}\right]^{+}$to $\left[\mathrm{P}_{666} \text { 14 }^{+} \text {and } \mathrm{b} \rightarrow \mathrm{c} \text { changing coordinating anion from [OAc] }\right]^{-}$to $\left[\mathrm{C}_{7} \mathrm{H}_{15} \mathrm{COO}\right]^{-}$( $\mathrm{Ln}=$ lanthanide). Illustration of the ordered state in the solid (left), with Coulombic attraction dominating and the transition via a glass state into a liquid (right) with predominantly van der Waals interactions.

Table 2. Thermal properties of the crystalline, glassy and liquid samples.

\begin{tabular}{cccc}
\hline Compound & $\mathrm{T}_{\mathrm{m}}{ }^{\mathrm{a}}\left({ }^{\circ} \mathrm{C}\right)$ & $\mathrm{T}_{\mathrm{g}}{ }^{\mathrm{b}}\left({ }^{\circ} \mathrm{C}\right)$ & $\mathrm{T}_{\mathrm{dec}^{\mathrm{c}}\left({ }^{\circ} \mathrm{C}\right)}$ \\
\hline$\left[\mathrm{C}_{4} \mathrm{Mim}\right]_{2}\left[\mathrm{Dy}_{2}\left(\mathrm{CH}_{3} \mathrm{COO}\right)_{8}\right]$ & 118 & - & 292 \\
{$\left[\mathrm{P}_{66614}\right]_{2}\left[\mathrm{Dy}_{2}\left(\mathrm{CH}_{3} \mathrm{COO}\right)_{8}\right]$} & - & -41.3 & 327 \\
{$\left[\mathrm{P}_{66614}\right]_{2}\left[\mathrm{Dy}\left(\mathrm{C}_{7} \mathrm{H}_{15} \mathrm{COO}\right)_{8}\right]$} & - & -80.4 & 354 \\
\hline
\end{tabular}

${ }^{\mathrm{a}}$ Melting point $\left(\mathrm{T}_{\mathrm{m}}\right),{ }^{\mathrm{b}}$ Glass transition $\left(\mathrm{T}_{\mathrm{g}}\right),{ }^{\mathrm{c}}$ Onset of decomposition $\left(\mathrm{T}_{\mathrm{dec}}\right)$.

These techniques combined give an overall insight into the physical properties of the studied systems. On their own, they are inadequate in confirming the hypothesis that the dimeric Dy ... Dysub-units established in the solid state are evident in the glass and liquid state. To gain a more in-depth understanding of the glass and liquid properties, the intrinsic magnetic properties of all three samples were investigated.

A superconducting quantum interference device (SQUID) magnetometer was employed to monitor the magnetic moment of each compound over a wide temperature range; it was hoped that an antiferromagnetic or ferromagnetic signature would be observed in the magnetic susceptibility of each respective compound, indicative of magnetic dimers beginning to order. The susceptibility and inverse susceptibility as a function of temperature for the crystalline solid, liquid and glass compounds, are available in the supplementary material (Figure S13) along with the results from Curie-Weiss fits to these data.

The susceptibility multiplied by the temperature as a function of temperature $\left(\mathrm{X}^{\mathrm{T}}\right)$, for the crystalline solid, liquid and glass compounds is presented in Figure 5. Here clear deviation from non-interacting behavior below $100 \mathrm{~K}$ for each compound is seen. The $\mathrm{X}^{\top}$ value that is predicted for two non-interacting Dy"l' ions $\left({ }^{6} \mathrm{H}_{15 / 2}\right.$ with $\left.\mathrm{g}=4 / 3^{[26]}\right)$ per formula unit is shown in Figure 5 by the dashed line. Considering the constant high temperature regions, it was found that the solid crystalline sample and the liquid sample yielded effective magnetic moments per Dy"II ion of $10.7 \mu_{\mathrm{B}}$ and $10.4 \mu_{\mathrm{B}}$, respectively. These values agree very well with the predicted value of $10.6 \mu_{\mathrm{B}}$, corresponding to two Dy'll ions per formula unit in the ground state ${ }^{6} \mathrm{H}_{15 / 2}$ with $\mathrm{g}=4 / 3 .{ }^{[26]}$ Regarding experimentally measured magnetic moments of Dy"l' ions, a range or $10.2-10.6 \mu_{\mathrm{B}}$ per Dy $\mathrm{y}^{\mathrm{III}}$ ion is observed in the literature ${ }^{[27-29]}$, with our previous work investigating monomeric lanthanide-based ionic liquids yielding a value of $10.2 \mu_{\mathrm{B}}$ per Dy"l' ion. ${ }^{\text {[22] }}$

We can conclude from Figure 5 that above $100 \mathrm{~K}$, we see no evidence of any interactions between Dy III ions. Below $100 \mathrm{~K}$ the measured XT values begin to deviate from that predicted for non-interacting magnetic moments. For Dy III ions, one cannot simply assume that a decrease in $\mathrm{X} T$ values directly corresponds to an antiferromagnetic coupling; the possibility that this decrease is due to a combination of dysprosium's magnetic anisotropy, progressive depopulation of the Stark levels - arising from crystal field splitting - and the exchange interaction ${ }^{[30]}$ must be entertained. A full numerical treatment isn't viable due to the large anisotropy of the Dy"l' ion. However, it is possible to make a rough quantitative model of the system. This method was first introduced by McPherson et al. ${ }^{[31]}$ and has been widely used to describe the magnetic behavior of lanthanide containing chemical compounds. ${ }^{[5,32-35]}$ The crux of the model is that the magnetic energy levels $\left(m_{J}\right)$ are considered LS coupled energy levels which are zero-field-split in an axial field geometry $\left(\hat{\mathrm{H}}=\Delta \hat{\mathrm{I}}_{\mathrm{Z}}^{2}\right)$ magnetic susceptibility of each Dy"l' ion is given by Equation 1 : 
$\chi_{D y}=\frac{N g^{2} \beta^{2}}{4 K T} \frac{A}{B}$

$A=225 e \frac{-225 \Delta}{4 K T}+169 e \frac{-169 \Delta}{4 K T}+121 e \frac{-121 \Delta}{4 K T}+81 e \frac{-81 \Delta}{4 K T}+49 e \frac{-49 \Delta}{4 K T}+$

$25 e \frac{-25 \Delta}{4 K T}+9 e \frac{-9 \Delta}{4 K T}+e \frac{-\Delta}{4 K T}$

$B=e \frac{-225 \Delta}{4 K T}+e \frac{-169 \Delta}{4 K T}+e \frac{-121 \Delta}{4 K T}+e \frac{-81 \Delta}{4 K T}+e \frac{-49 \Delta}{4 K T}+e \frac{-25 \Delta}{4 K T}+e \frac{-9 \Delta}{4 K T}+e \frac{-\Delta}{4 K T}$

The interactions between magnetic moments are simulated by incorporating the Weiss parameter according to Equation 2:

$\chi_{M}=\frac{T}{T-\theta} 2 \chi_{D y}$

Through fitting the data, it is possible to extract numerical values for the zero-field-splitting parameter $(\Delta)$, the temperature at which magnetic ordering occurs $(\theta)$ along with the g-factor $(g)$ for each system. Applying the model to each dataset by method of a non-linear least squares fitting resulted in the values displayed in Table 3 . The resulting fits are plotted on top of the experimental data points in Figure 5, showing good agreement.

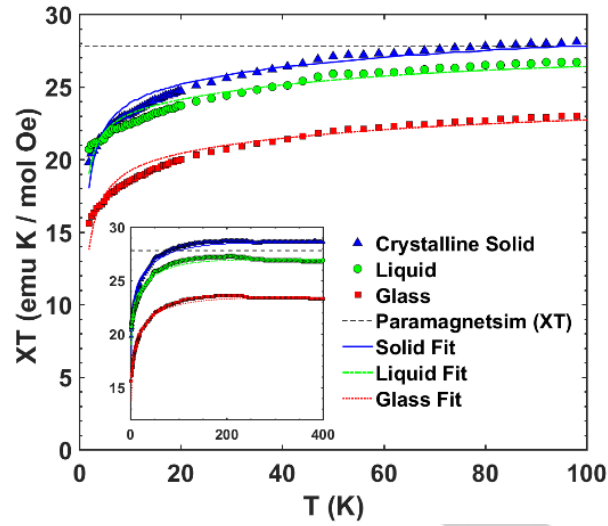

Figure 5. Susceptibility multiplied by the temperature as a function of temperature. Fit including interactions and zero-field splitting.

The fit parameters from equations [1] and [2] are presented in Table 3Table for all three samples, along with parameters for two compounds from literature. The numerical value of the zero-field splitting parameter obtained for all three compounds are very similar, implying they experience very similar zero field splitting, as expected since the Dy'II ions in each respective compound are in very similar coordination environments.

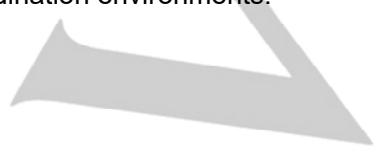

Table 3. Results of the non-linear least squares fitting applied to the model developed by McPherson et al

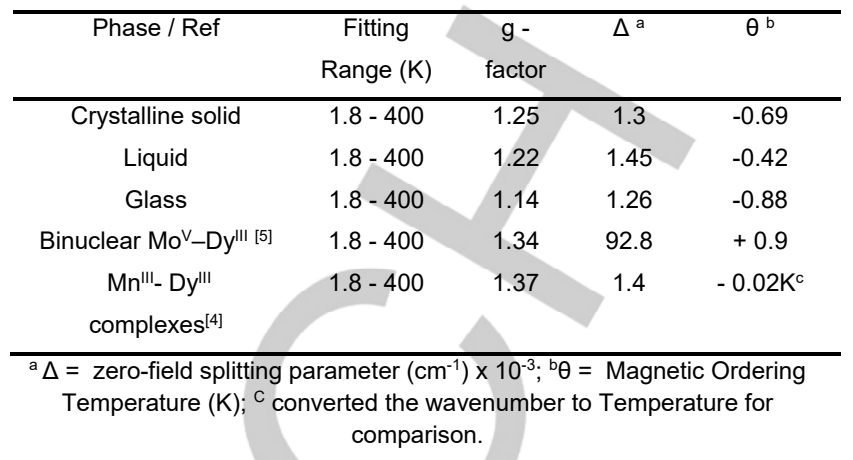

It is the ligands that differ and give rise to the observed phase changes between compounds. The zero-field splitting parameters found for the samples here are of the same order of magnitude as those reported in literature. ${ }^{[4,5]}$ The magnetic ordering temperatures obtained for all compounds are under $1 \mathrm{~K}$; this is as expected due to the localized nature of the $4 \mathrm{f}$ magnetism exhibited by RE ions. The Weiss parameters for all three compounds are identical, within uncertainty This implies that the distance between the ions are the same, since the magnetic interaction decreases with distance between moments. Simply fitting using equation (1), ignoring the Weiss parameter for antiferromagnetic interaction, does not accurately reproduce the data (Figure S14 in the supplementary material). Hence, the decrease in $X T$ at low temperatures must be a combination of both depopulation (zero field splitting) effects and antiferromagnetism. This holds for all the datasets and is consistent with magnetic dimers being present in all the measured compounds, with magnetic ordering temperatures under $1 \mathrm{~K}$.

Herein, we demonstrate the design from crystalline to glass and most importantly, liquid dimeric Dy"l' containing ionic compounds. Since speciation of metals in the liquid state can be a challenge, we have developed an innovative approach by using the magnetic properties to prove metal-metal interactions within the dimeric structure in the liquid phase. The same antiferromagnetic signature was observed in the crystalline, glass and liquid compounds a strong indicator that the magnetic dimers formed in the crystalline solid were in fact formed in the glass and liquid state as well.

\section{Experimental Section}

Experimental details can be found in the supplementary information.

\section{Acknowledgements}

The authors gratefully acknowledge the financial support from The Engineering and Physical Research Science Council (EPRSC) (E.M. 
PhD funding, S3802ASA), as well as the Royal Society (Grant RG130739). SF and KE acknowledge support from DfE (Department for the Economy, Northern Ireland) through grant USI 108.

Keywords: Dimer • Ionic Liquids • Lanthanides • Magnetic Properties • Materials Chemistry

[1] J.-C. G. Bünzli, C. Piguet, Chem. Soc. Rev. 2005, 34, 1048

[2] B. Mallick, B. Balke, C. Felser, A.-V. Mudring, Angew. Chemie Int. Ed. 2008, 47, 7635-7638.

[3] J.-P. Costes, F. Dahan, A. Dupuis, S. Lagrave, J.-P. Laurent, Inorg. Chem. 1998, 37, 153-155.

[4] D.-Z. Liao, Yu-Zhang Tong, Qing-Lun Wang, Ai-Ping Zhang, Yue Ma, Shi-Ping Yan, Guang-Ming Yang, Peng Cheng, Inorg. Chem. Commun. 2013, 32, 32-36.

[5] S. Ren, S. L. Ma, G. F. Xu, B. Gu, Y. Ma, Q. L. Wang, D. Z. Liao, Inorg. Chem. Commun. 2011, 14, 1124-1127.

[6] A. Ouchi, Y. Suzuki, Y. Ohki, Y. Koizumi, Coord. Chem. Rev. 1988, 92, 29-43.

[7] D. N. Woodruff, R. E. P. Winpenny, R. A. Layfield, Chem. Rev. 2013, 113, 5110-5148.

[8] P. Wasserscheid, T. Welton, Ionic Liquids in Synthesis, Wiley-VCH, 2002.

[9] P. Wasserscheid, W. Keim, Angew. Chemie 2000, 39, 3772-3789.

[10] T. Welton, Chem. Rev. 1999, 99, 2071-2084.

[11] M. Freemantle, An Introduction to Ionic Liquids, RSC Pub, 2010.

[12] A. E. Visser, J. D. Holbrey, R. D. Rogers, Chem. Commun. 2001, 2484-2485.

[13] Y. Yoshida, I. Fujii, K. Muroi, A. Otsuka, G. Saito, M. Takahashi, T. Yoko, Synth. Met. 2005, 153, 421-424.

[14] S. Hayashi, H.-O. Hamaguchi, Chem. Lett. 2004, 33, 1590-1591.

[15] E. Santos, J. Albo, A. Irabien, RSC Adv. 2014, 4, 40008-40018.

[16] R. E. Del Sesto, T. M. Mccleskey, A. K. Burrell, G. A. Baker, J. D. Thompson, B. L. Scott, J. S. Wilkes, P. Williams, Chem. Commun 2008, 4, 447-449. S. Pitula, A. V. Mudring, Chem. - A Eur. J. 2010, 16, 3355-3365.
[19]

I. De Pedro, D. P. Rojas, J. Albo, P. Luis, A. Irabien, J. Us, A. Blanco, J. Rodríguez Fernández, J. Phys. Condens. Matter 2010, 22, 296006-4.

[20] P. Nockemann, B. Thijs, N. Postelmans, K. Van Hecke, L. Van Meervelt, K. Binnemans, J. Am. Chem. Soc. 2006, 128, 1365813659.

[21] D. Prodius, F. Macaev, Y. Lan, G. Novitchi, S. Pogrebnoi, E. Stingaci, V. Mereacre, C. E. Anson, A. K. Powell, Chem. Commun. Chem. Commun 2013, 49, 9215-9217.

[22] J. Alvarez-Vicente, S. Dandil, D. Banerjee, H. Q. N. Gunaratne, S. Gray, S. Felton, G. Srinivasan, A. M. Kaczmarek, R. Van Deun, P. Nockemann, J. Phys. Chem. B 2016, 120, 5301-5311.

[23] T. C. Monson, T. E. Stevens, J. L. Leger, J. L. Manson, K. S. Lovejoy, A. L. Newsham, R. E. Del Sesto, Chem. Commun. 2017, 53, 11682-11685.

[24] P. Nockemann, B. Thijs, K. Lunstroot, T. N. Parac-Voet, C. GörllerWalrand, K. Binnemans, K. Van Hecke, L. Van Meervelt, S. Nikitenko, J. Daniels, et al., Chem. Eur. J. 2009, 15, 1449-1461.

[25] G. B. Deacon, R. J. Phillips, Coord. Chem. Rev. 1980, 33.

[26] J. M. D. Coey, Magnetism and Magnetic Materials, Cambridge University Press, Cambridge, 2010.

[27] Y. Peng, V. Mereacre, C. Anson, A. Powell, Inorganics 2016, 4, 2.

[28] L. Liu, Y. Li, S. X. Deng, Y. P. Zhang, Inorganica Chim. Acta 2017, 457, 1-6.

[29] P. Comba, M. Großhauser, R. Klingeler, C. Koo, Y. Lan, D. Müller, J. Park, A. Powell, M. J. Riley, H. Wadepohl, Inorg. Chem. 2015, 54, 11247-11258.

[30] C. J. O'Connor, in Prog. Inorg. Chem. (Ed.: S.J. Lippard), Wiley, 2007, pp. 203-282.

[31] I. A. Kahwa, J. Selbin, C. J. O'Connor, J. W. Foise, G. L. McPherson, Inorganica Chim. Acta 1988, 148, 265-272.

[32] B. Li, W. Gu, L.-Z. Zhang, J. Qu, Z.-P. Ma, X. Liu, D.-Z. Liao, Inorg. Chem. 2006, 45, 10425-10427.

[33] N. Xu, W. Shi, D. Z. Liao, S. P. Yan, P. Cheng, Inorg. Chem. 2008, 47, 8748-8756.

[34] N. Xu, C. Wang, W. Shi, S. P. Yan, P. Cheng, D. Z. Liao, Eur. J. Inorg. Chem. 2011, 2387-2393.

[35] J.-K. Tang, Q.-L. Wang, S.-F. Si, D.-Z. Liao, Z.-H. Jiang, S.-P. Yan, P. Cheng, Inorganica Chim. Acta 2004, 325-330.
K. Lehmann, S. P. Verevkin, A. Heintz, Angew. Chemie Int. Ed. 2010, 49, 7116-7119. 


\section{Entry for the Table of Contents}

\section{COMMUNICATION}

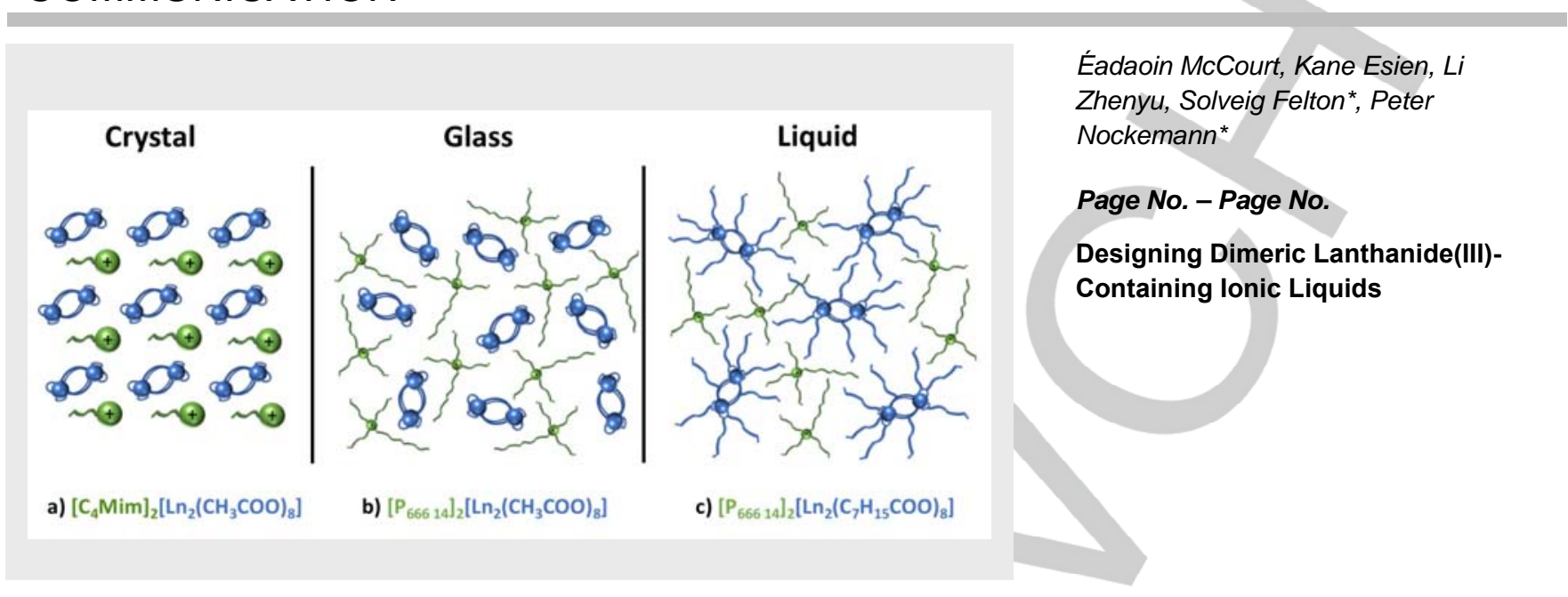

Variation in anion and cation structure upon changing from crystalline solid to glass to liquid dimeric lanthanide-containing compounds. 


\section{Supporting Information \\ CWiley-VCH 2016 \\ 69451 Weinheim, Germany}

\section{Designing Dimeric Lanthanide(III)-Containing lonic Liquids}

Éadaoin McCourt, Kane Esien, Li Zhenyu, Solveig Felton, * and Peter Nockemann*

\section{Table of Contents}

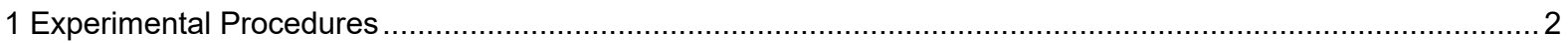

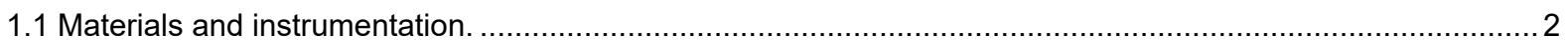

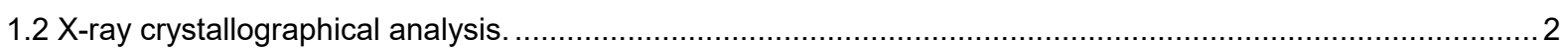

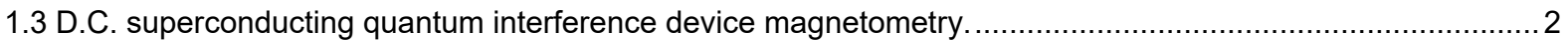

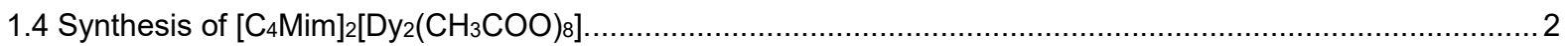

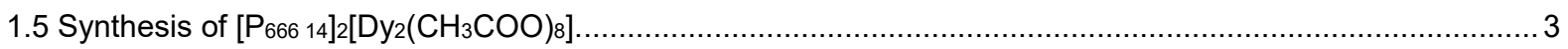

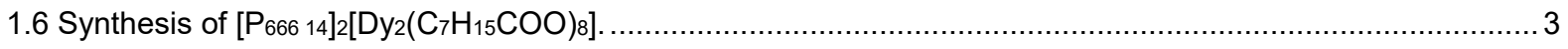

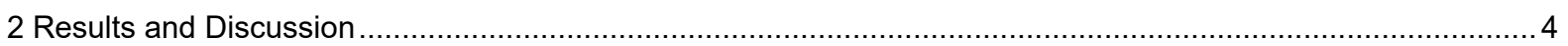

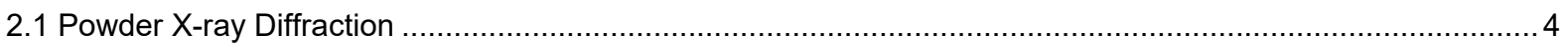

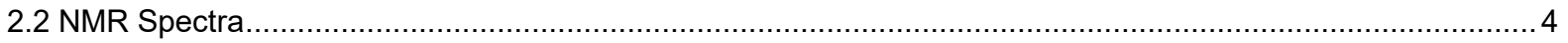

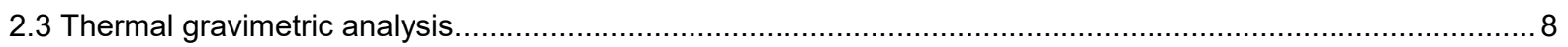

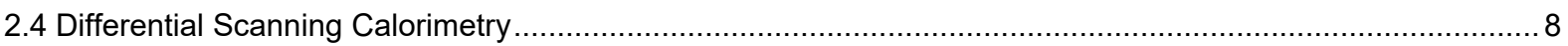

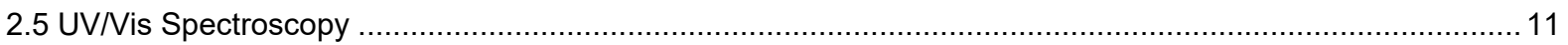

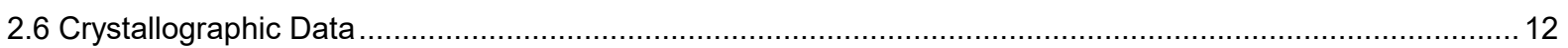

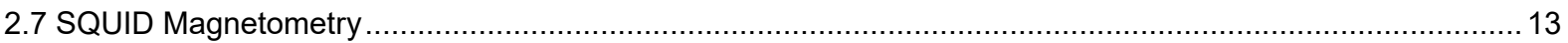

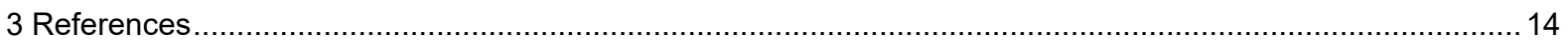

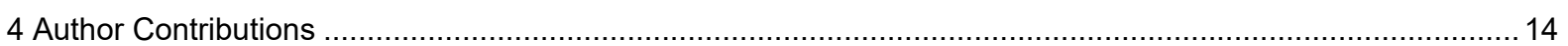




\section{Experimental Procedures}

\subsection{Materials and instrumentation.}

Dy $\left(\mathrm{CH}_{3} \mathrm{COO}\right)_{3} \cdot 4 \mathrm{H}_{2} \mathrm{O}$, chemical grade, $99.9 \%$ and sodium acetate anhydrous, $99 \%$ were purchased from Alfa Aesar. $\left[\mathrm{C}_{4} \mathrm{Mim}\right]\left[\mathrm{CH}_{3} \mathrm{COO}\right], \geq 95 \%$ was purchased from Sigma Aldrich. $\left[\mathrm{P}_{666}{ }_{14}\right][\mathrm{Cl}]$ was purchased from Cytec and used without further purification. Nuclear magnetic resonance (NMR) spectra were recorded on a Bruker $400 \mathrm{MHz}$ ultrashield spectrometer. TGA and DSC were conducted on a TA Q5000 and Q2000 equipped with a refrigerated cooling system 90 (temperature range -90 $150{ }^{\circ} \mathrm{C}$ ) and auto-sampler, respectively. In addition, elemental analysis was determined using a PerkinElmer 2400 series 2 CHNS/O analyser. FTIR was carried out on a PerkinElmer Spectrum 100 spectrometer and UV/Vis spectra were recorded on an Agilent, Cary 60 spectrophotometer.

\section{$1.2 \mathrm{X}$-ray crystallographical analysis.}

Crystal data collection was performed on a Rigaku Single Crystal X-ray diffractometer, equipped with cryostat. Measurements were carried out at $100 \mathrm{~K}$ using a Cu Ka, monochromator, $\lambda=1.54184 \AA$. Using Olex2, the structure was solved with the ShelXT structure solution program using Intrinsic Phasing and further refined with the ShelXL refinement package using least squares minimisation.

\subsection{D.C. superconducting quantum interference device magnetometry.}

The DC magnetic susceptibility of samples presented in this paper were measured using a Quantum Design MPMS XL SQUID, utilizing the reciprocal sample option (RSO). The magnetization was measured over a temperature range of 1.8 to $400 \mathrm{~K}$. All samples were zero-field cooled from $400 \mathrm{~K}$ down to $1.8 \mathrm{~K}$, and upon reaching the lowest temperature a field of 500 Oe was applied. The sample was then heated from 1.8 to $400 \mathrm{~K}$ in the applied field. Measurements of the magnetization were taken in $0.5 \mathrm{~K}$ intervals (when $\mathrm{T}<20 \mathrm{~K}$ ) and $3 \mathrm{~K}$ intervals (when $\mathrm{T}>20 \mathrm{~K}$ ) and the temperature was allowed to stabilize prior to any measurements being made. For verification of the paramagnetic behaviour (non-hysteretic behaviour) of the samples, data were collected upon cooling and warming and no differences were observed between the two protocols. Diamagnetic corrections were calculated for the relevant chemical structures using Pascal's constants and applied to all data. ${ }^{[1]}$ The measurement of the magnetic moment in our MPMS SQUID has an uncertainty of $5 \%$ which arises mainly from differences in sample mounting and cannot be eliminated.

\subsection{Synthesis of $\left[\mathrm{C}_{4} \mathrm{Mim}\right]_{2}\left[\mathrm{Dy}_{2}\left(\mathrm{CH}_{3} \mathrm{COO}\right)_{8}\right]$.}

To a GC sample vial $\left[\mathrm{C}_{4} \mathrm{Mim}\right]\left[\mathrm{CH}_{3} \mathrm{COO}\right](59 \mathrm{mg}, 0.297 \mathrm{mmol})$ and $\mathrm{Dy}\left(\mathrm{CH}_{3} \mathrm{COO}\right)_{3} \cdot 4 \mathrm{H}_{2} \mathrm{O}(122.5 \mathrm{mg}, 0.297 \mathrm{mmol})$ were added. The vial was sealed and wrapped in aluminium foil and placed in a Reacti-Therm to be slowly heated to $120^{\circ} \mathrm{C}$. The vial was subsequently cooled over a period of $48 \mathrm{~h}$ to allow $\left[\mathrm{C}_{4} \mathrm{Mim}_{2}\left[\mathrm{Dy}_{2}\left(\mathrm{CH}_{3} \mathrm{COO}\right)_{8}\right]\right.$ crystals to form. Anal. Calcd for $\mathrm{C}_{32} \mathrm{H}_{54} \mathrm{O}_{16} \mathrm{~N}_{4} \mathrm{Dy} \mathrm{Dy}_{2} \mathrm{C}$, 35.73; H, 5.06; N, 5.21. Found: C, 35.37; H, 4.99; N, 5.81. 


\subsection{Synthesis of $\left[\mathrm{P}_{666}\right.$ 14 $_{2}\left[\mathrm{Dy}_{2}\left(\mathrm{CH}_{3} \mathrm{COO}\right)_{8}\right]$.}

$\left[\mathrm{P}_{66614}\right]\left[\mathrm{CH}_{3} \mathrm{COO}\right]$ was prepared as follows; To a solution of $\left[\mathrm{P}_{666} 1_{14}\right][\mathrm{Cl}](5.1 \mathrm{~g}, 9.82 \mathrm{mmol})$ in ethanol, $\mathrm{Na}\left(\mathrm{CH}{ }_{3} \mathrm{COO}\right)(0.81 \mathrm{~g}, 9.82$ $\mathrm{mmol}$ ) dissolved in ethanol was added. The reaction was left to stir for 48 hours at room temperature. Büchner filtration was used to remove the by-product $\mathrm{NaCl}$. The ethanol was removed by rotary evaporation at $60^{\circ} \mathrm{C}$. Centrifugation was necessary to further remove $\mathrm{NaCl}$. The final product was dried under vacuum at $70{ }^{\circ} \mathrm{C}$. A pale yellow viscous liquid was obtained. ${ }^{1} \mathrm{H} \mathrm{NMR}$ (Supplementary Fig. S2) (400 MHz, $\left.\mathrm{CDCl}_{3}\right): \delta=2.43(\mathrm{~m}, 8 \mathrm{H}), 1.94(\mathrm{~s}, 3 \mathrm{H}), 1.47-1.24(\mathrm{~m}, 48 \mathrm{H}), 0.90-0.85(\mathrm{~m}, 12 \mathrm{H}) \mathrm{ppm}$. ${ }^{13} \mathrm{C}$ NMR (Supplementary Fig. S3) (100 MHz, $\left.\mathrm{CDCl}_{3}\right): \delta=176.86(\mathrm{COO}), 31.91\left(\mathrm{CH}_{2} \mathrm{COO}\right), 30.90-21.88\left(\mathrm{CH}_{2}\right), 19.17\left(\mathrm{CH}_{3}\right)$, 14.10 $\left(\mathrm{PCH}_{2}\right)$ ppm. ${ }^{31} \mathrm{P}$ NMR (Supplementary Fig. S4) (162 MHz, $\left.\mathrm{CDCl}_{3}\right): \delta=33.02 \mathrm{ppm}$.

In a sealed vial $\left[\mathrm{P}_{66614}\right]\left[\mathrm{CH}_{3} \mathrm{COO}\right](166 \mathrm{mg}, 0.31 \mathrm{mmol})$ was then added to $\mathrm{Dy}\left(\mathrm{CH}_{3} \mathrm{COO}\right)_{3} \cdot 4 \mathrm{H}_{2} \mathrm{O}(129.22 \mathrm{mg}, 0.31 \mathrm{mmol})$ and the reaction mixture was stirred for 24 hours at $80^{\circ} \mathrm{C}$. The product was obtained as a pale-yellow glass.

\subsection{Synthesis of $\left[\mathrm{P}_{666}{ }_{14}\right]_{2}\left[\mathrm{Dy}_{2}\left(\mathrm{C}_{7} \mathrm{H}_{15} \mathrm{COO}\right)_{8}\right]$.}

$\left[\mathrm{P}_{66614}\right]\left[\mathrm{C}_{7} \mathrm{H}_{15} \mathrm{COO}\right]$ and $\mathrm{Dy}\left(\mathrm{C}_{7} \mathrm{H}_{15} \mathrm{COO}\right)_{3} \cdot \mathrm{xH}_{2} \mathrm{O}$ were prepared according to previously reported literature ${ }^{[2],[3]}$ described as follows; octanoic acid $(5.53 \mathrm{~g}, 38.4 \mathrm{mmol})$ and $\left[\mathrm{P}_{66614}\right] \mathrm{Cl}(19.94 \mathrm{~g}, 38.4 \mathrm{mmol})$ were dissolved in $75 \mathrm{~mL}$ of hexane. A solution of $\mathrm{NaOH}$ ( $1.54 \mathrm{~g}, 38.4 \mathrm{mmol}$, in $75 \mathrm{~mL}$ of $\mathrm{H}_{2} \mathrm{O}$ ) was added dropwise at room temperature (RT). The mixture was stirred at RT overnight. The upper organic phase was separated and washed four times with $\mathrm{H}_{2} \mathrm{O}$. Solvent was removed by rotary evaporator and the product was dried at $70^{\circ} \mathrm{C}$ under vacuum for 24 hours to yield $\left[\mathrm{P}_{66614}\right]\left[\mathrm{C}_{7} \mathrm{H}_{15} \mathrm{COO}\right]$ as a viscous liquid. Dy $\left(\mathrm{C}_{7} \mathrm{H}_{15} \mathrm{COO}\right)_{3}$ was synthesised according to previously reported syntheses by Binnemans et al. ${ }^{[3]}$ Octanoic acid was dissolved in an ethanol/water mixture and transformed to sodium octanoate by adding an equivalent amount of $1 \mathrm{M} / \mathrm{L} \mathrm{NaOH}$ standard aqueous solution (addition dropwise via a burette). Dy (III) nitrate hydrate was dissolved in $100 \mathrm{~mL}$ ethanol/water mixture and added dropwise to the sodium octanoate solution. Upon addition a white precipitate formed immediately. The reaction was left to stir for a further 1 hour after which the white precipitate was filtered and washed with ethanol/water mixture and the product was dried overnight at $30^{\circ} \mathrm{C}$. Dy octanoate was obtained as a fine white powder. $\left[\mathrm{P}_{666}{ }_{14}\right]_{2}\left[\mathrm{Dy}_{2}\left(\mathrm{C}_{7} \mathrm{H}_{15} \mathrm{COO}\right)_{8}\right]$ : In a sealed vial $\left[\mathrm{P}_{666614}\right]\left[\mathrm{C}_{7} \mathrm{H}_{15} \mathrm{COO}\right](166 \mathrm{mg}, 0.26$ mmol) was added to $\mathrm{Dy}\left(\mathrm{C}_{7} \mathrm{H}_{15} \mathrm{COO}\right)_{3}(156.74 \mathrm{mg}, 0.26 \mathrm{mmol})$ under inert conditions to minimise the influence of water and the reaction mixture was stirred for 24 hours in ethanol at $70{ }^{\circ} \mathrm{C}$. $\left[\mathrm{P}_{666}{ }_{14}\right]_{2}\left[\mathrm{Dy}_{2}\left(\mathrm{C}_{7} \mathrm{H}_{15} \mathrm{COO}\right)_{8}\right]$ was obtained as a transparent pale viscous liquid. $\left[\mathrm{P}_{66614}\right]\left[\mathrm{C}_{7} \mathrm{H}_{15} \mathrm{COO}\right]{ }^{1} \mathrm{H}$ NMR (Supplementary Fig. S5 (400 MHz, $\left.\mathrm{CDCl}_{3}\right) \delta 2.44(\mathrm{~m}, \mathrm{~J}=14.3 \mathrm{~Hz}, 8 \mathrm{H}), 2.15(\mathrm{t}, \mathrm{J}=$ $15.6 \mathrm{~Hz}, 2 \mathrm{H}), 1.58-1.45(\mathrm{~m}, 18 \mathrm{H}), 1.32-1.21(\mathrm{~m}, 40 \mathrm{H}), 0.86-0.80(\mathrm{~m}, 15 \mathrm{H})$ ppm. ${ }^{13} \mathrm{C}$ NMR (Supplementary Fig. S6) (100 $\left.\mathrm{MHz}, \mathrm{CDCl}_{3}\right): \delta=180.40(\mathrm{COO}), 39.30\left(\mathrm{CH}_{2} \mathrm{COO}\right), 31.94-21.91\left(\mathrm{CH}_{2}\right), 19.15\left(\mathrm{CH}_{3}\right), 14.07\left(\mathrm{P}-\mathrm{CH}_{2}\right) \mathrm{ppm} .{ }^{31} \mathrm{P} \mathrm{NMR}$ (Supplementary Fig. S7) (162 MHz, $\mathrm{CDCl}_{3}$ ): $\delta=32.98$ ppm. Anal. Calcd for $\mathrm{C}_{80} \mathrm{H}_{160} \mathrm{O}_{16} \mathrm{P}_{2} \mathrm{Dy}$ : $\mathrm{C}, 63.05 ; \mathrm{H}, 10.58$. Found: C, 65.39; H, 11.46 . 
2 Results and Discussion

2.1 Powder X-ray Diffraction

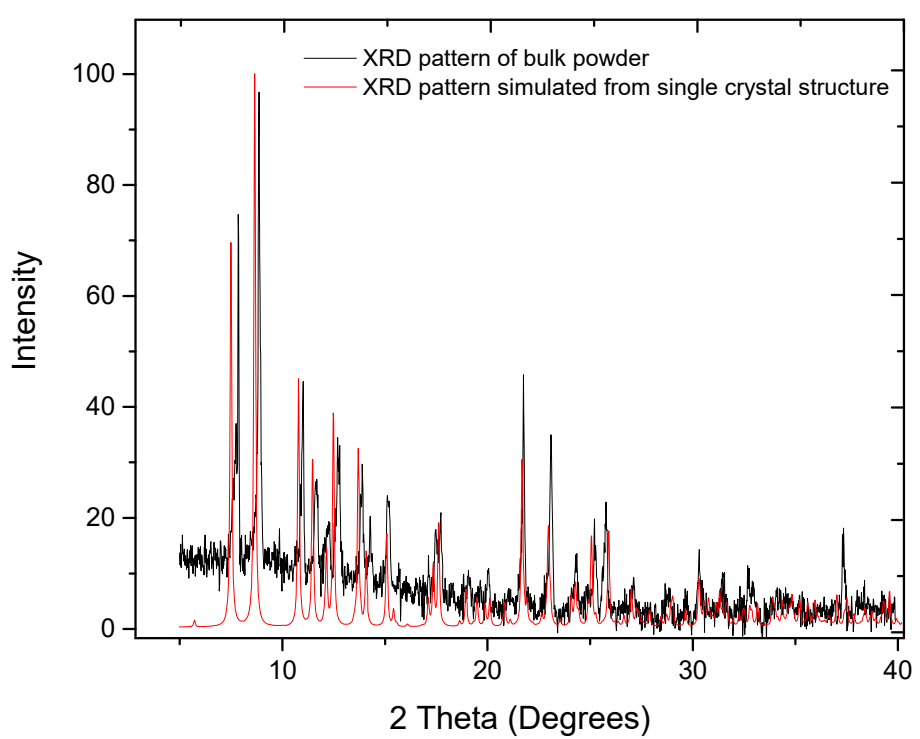

Figure S1. Powder XRD pattern of the bulk $\left[\mathrm{C}_{4} \mathrm{Mim}\right]_{2}\left[\mathrm{Dy}_{2}\left(\mathrm{CH}_{3} \mathrm{COO}\right)_{8}\right]$ sample (black) and pattern simulated from single crystal structure (red).

\subsection{NMR Spectra}

Trihexyltetra(decyl)phosphonium acetate $\left(\left[\mathrm{P}_{666} 14\right]\left[\mathrm{CH}_{3} \mathrm{COO}\right]\right)$

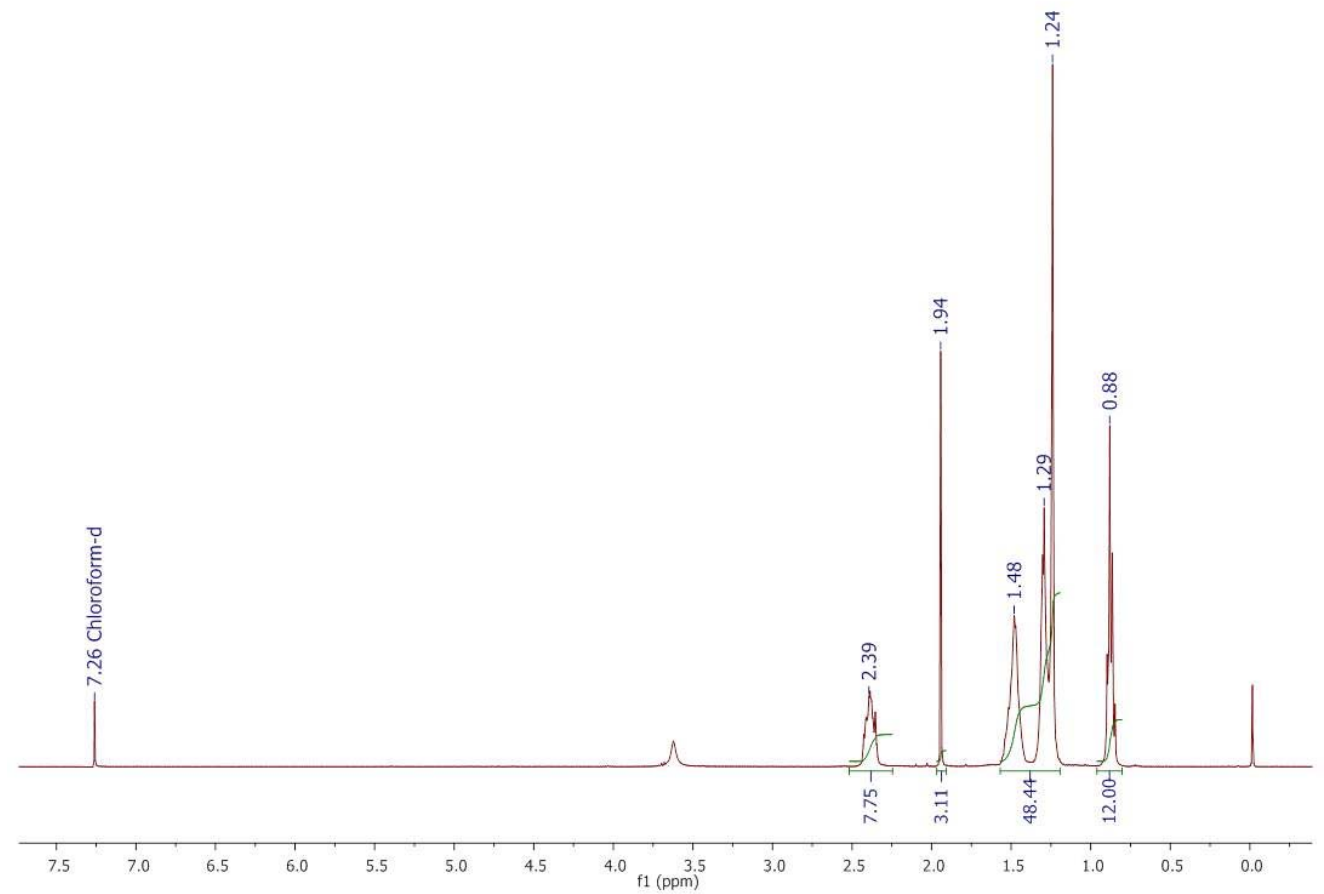

Figure S2. ${ }^{1} \mathrm{H}$ NMR spectrum of $\left[\mathrm{P}_{666} 14\right]\left[\mathrm{CH}_{3} \mathrm{COO}\right]$. 


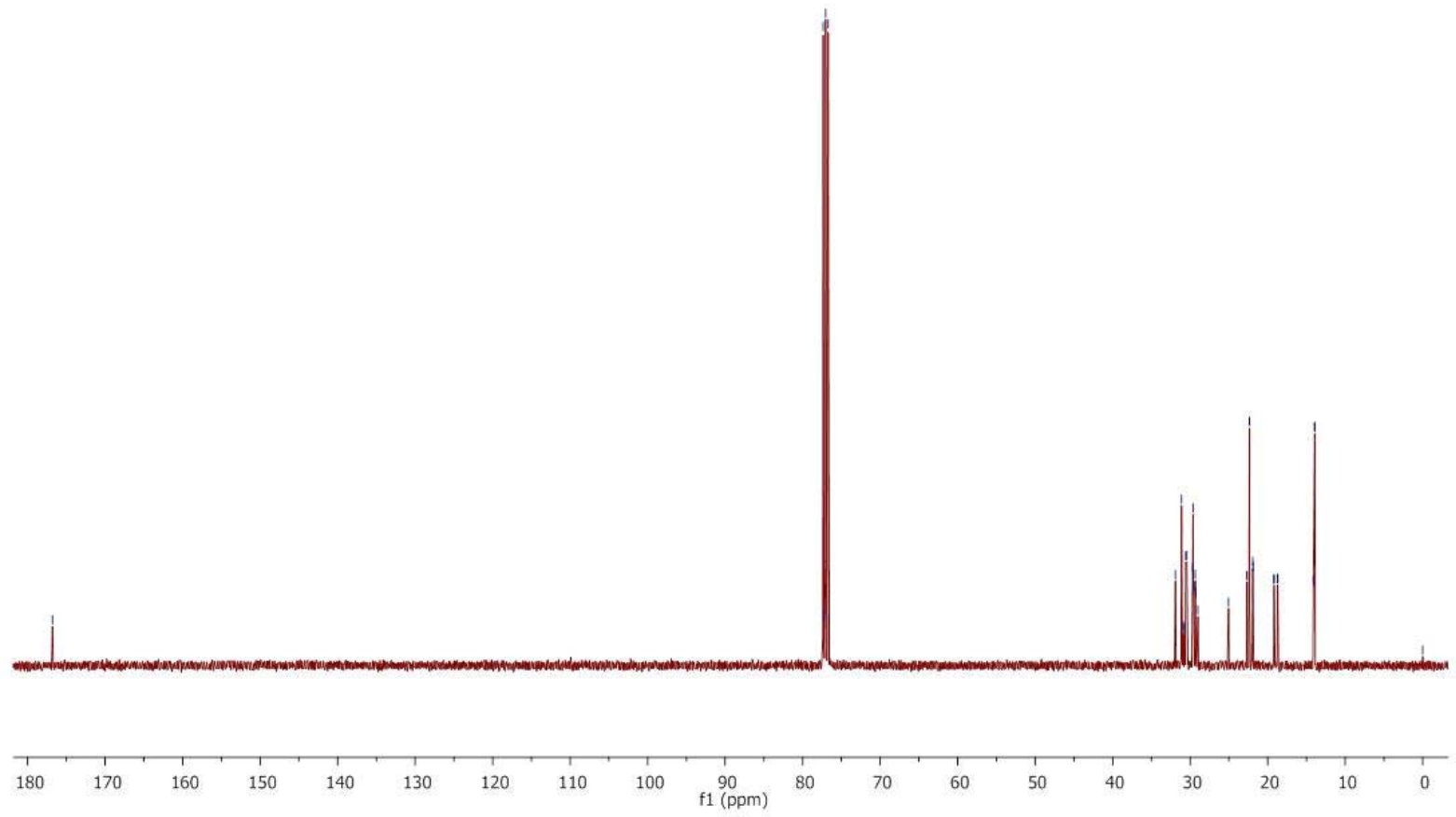

Figure S3. ${ }^{13} \mathrm{C}$ NMR spectrum of $\left[\mathrm{P}_{666}{ }_{14}\right]\left[\mathrm{CH}_{3} \mathrm{COO}\right]$.

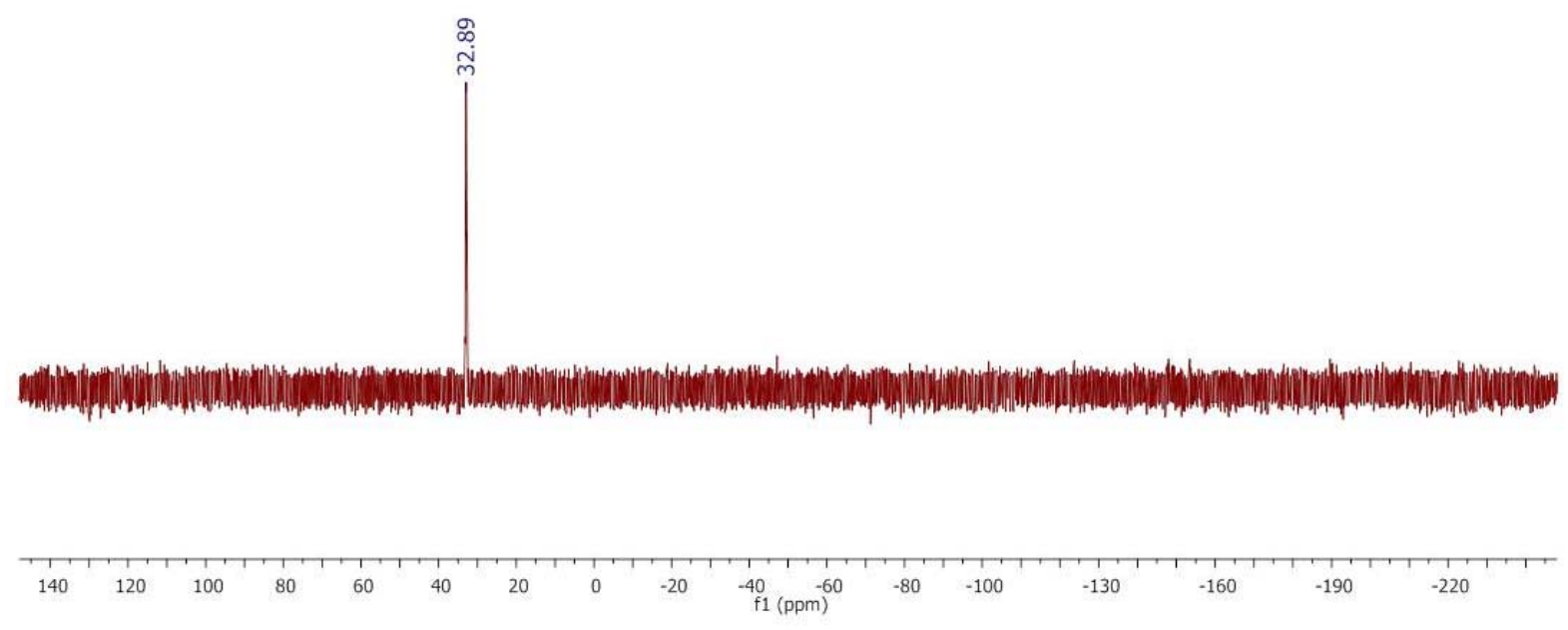

Figure S4. ${ }^{31} \mathrm{P}$ NMR spectrum of $\left[\mathrm{P}_{666} 14\right]\left[\mathrm{CH}_{3} \mathrm{COO}\right]$. 
Trihexyltetra(decyl)phosphonium octanoate $\left(\left[\mathrm{P}_{666}{ }_{14}\right]\left[\mathrm{C}_{7} \mathrm{H}_{15} \mathrm{COO}\right]\right)$

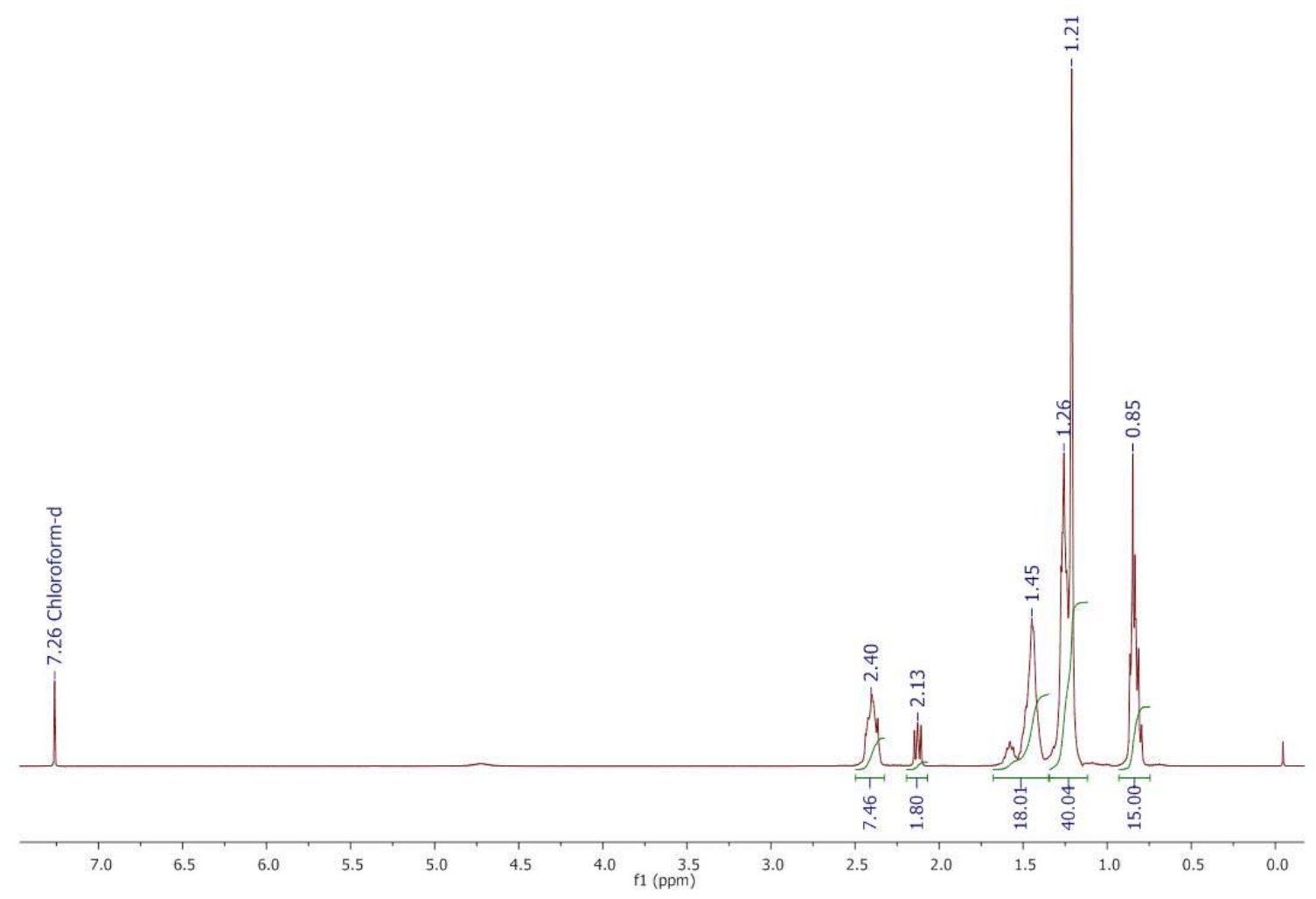

Figure S5. ${ }^{1} \mathrm{H}$ NMR spectrum of $\left[\mathrm{P}_{666}{ }_{14}\right]\left[\mathrm{C}_{7} \mathrm{H}_{15} \mathrm{COO}\right]$. 


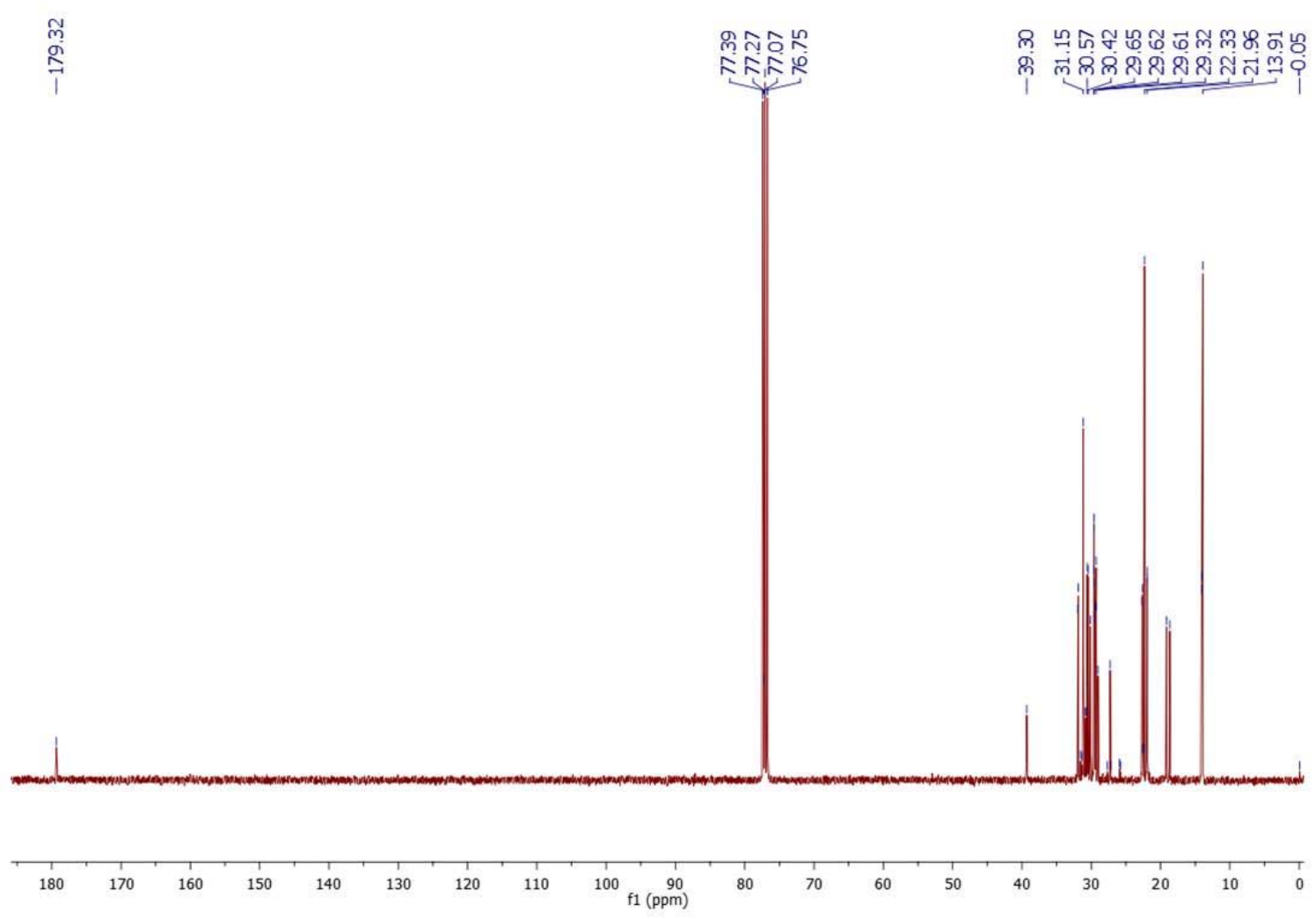

Figure S6. ${ }^{13} \mathrm{C}$ NMR spectrum of $\left[\mathrm{P}_{666}{ }_{14}\right]\left[\mathrm{C}_{7} \mathrm{H}_{15} \mathrm{COO}\right]$.

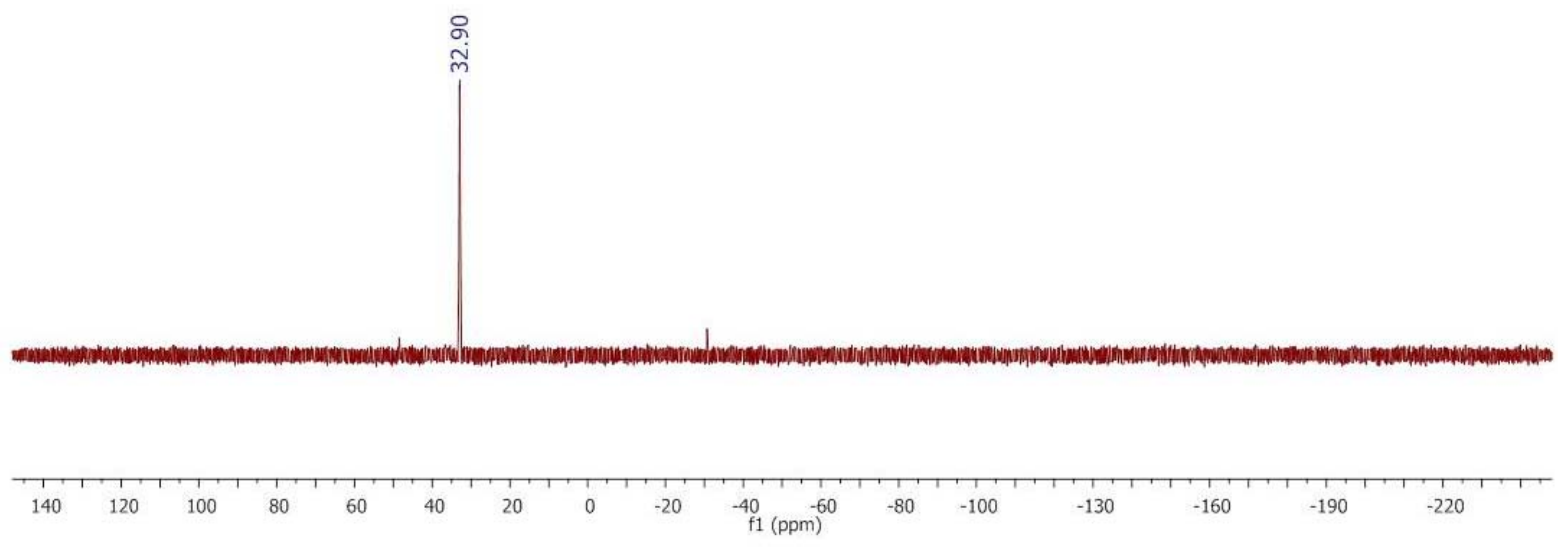

Figure S7. ${ }^{31} \mathrm{P}$ NMR spectrum of $\left[\mathrm{P}_{666}{ }_{14}\right]\left[\mathrm{C}_{7} \mathrm{H}_{15} \mathrm{COO}\right]$. 


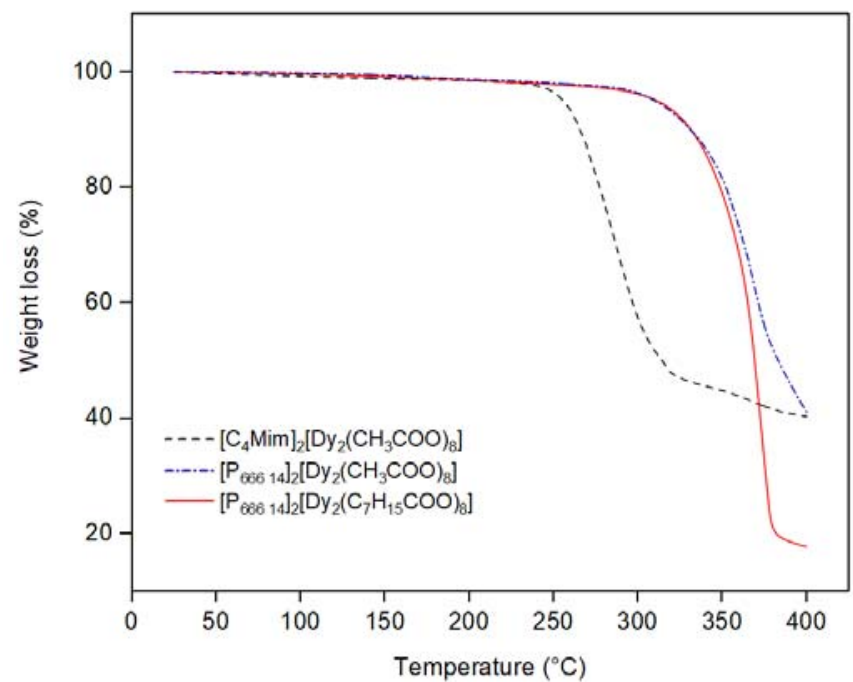

Figure S8. TGA of $\left[\mathrm{C}_{4} \mathrm{Mim}\right]_{2}\left[\mathrm{Dy}_{2}\left(\mathrm{CH}_{3} \mathrm{COO}\right)_{8}\right]$ (black dash), $\left[\mathrm{P}_{666} 1_{14}\right]_{2}\left[\mathrm{Dy}_{2}\left(\mathrm{CH}_{3} \mathrm{COO}\right)_{8}\right]$ (blue) and $\left[\mathrm{P}_{666}\right.$ 14 $_{2}\left[\mathrm{Dy}_{2}\left(\mathrm{C}_{7} \mathrm{H}_{15} \mathrm{COO}\right)_{8}\right](\mathrm{red})$.

\subsection{Differential Scanning Calorimetry}

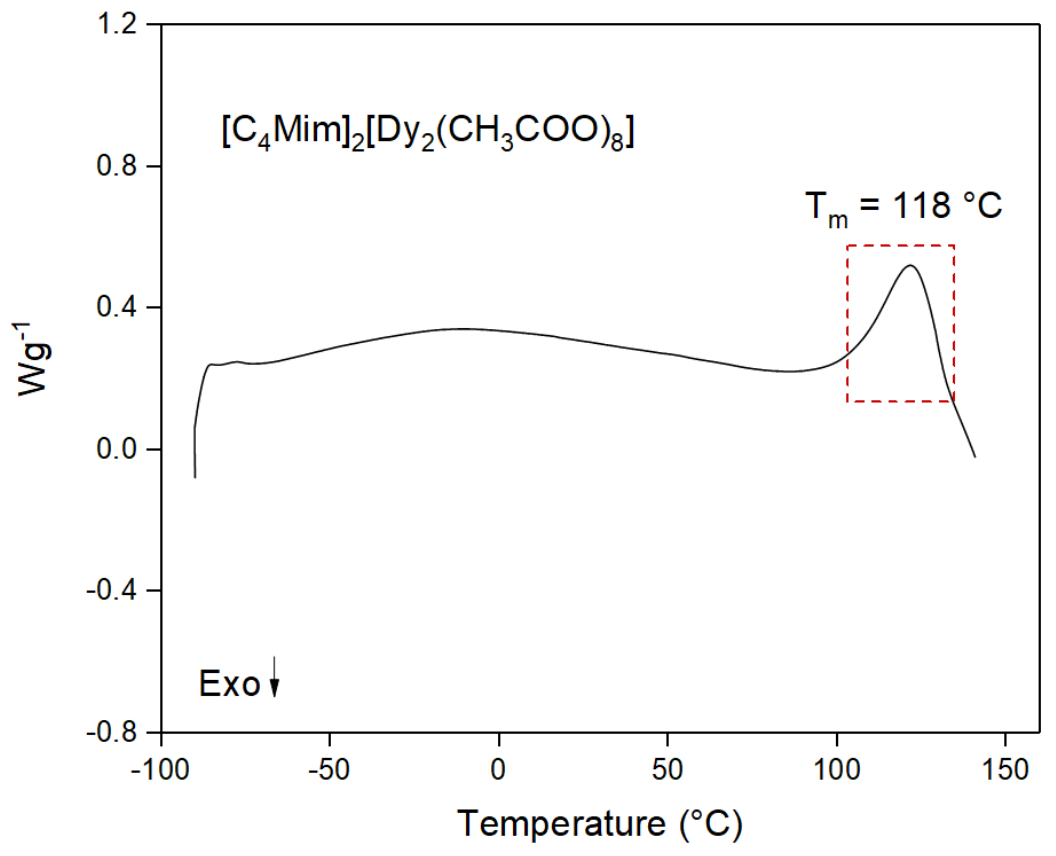

Figure S9. DSC of $\left[\mathrm{C}_{4} \mathrm{Mim}\right]_{2}\left[\mathrm{Dy}{ }_{2}\left(\mathrm{CH}_{3} \mathrm{COO}\right)_{8}\right]$ 


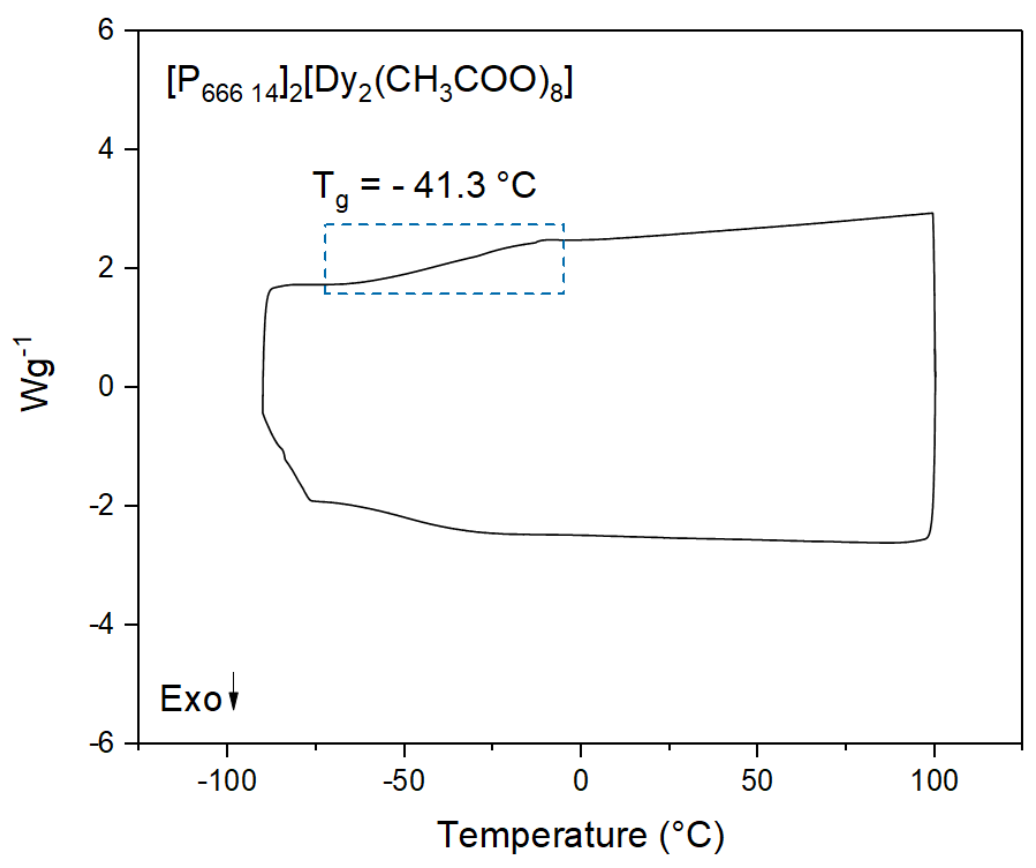

Figure S10. DSC of $\left[\mathrm{P}_{666} 1_{4}\right]_{2}\left[\mathrm{Dy}_{2}\left(\mathrm{CH}_{3} \mathrm{COO}\right)_{8}\right]$.

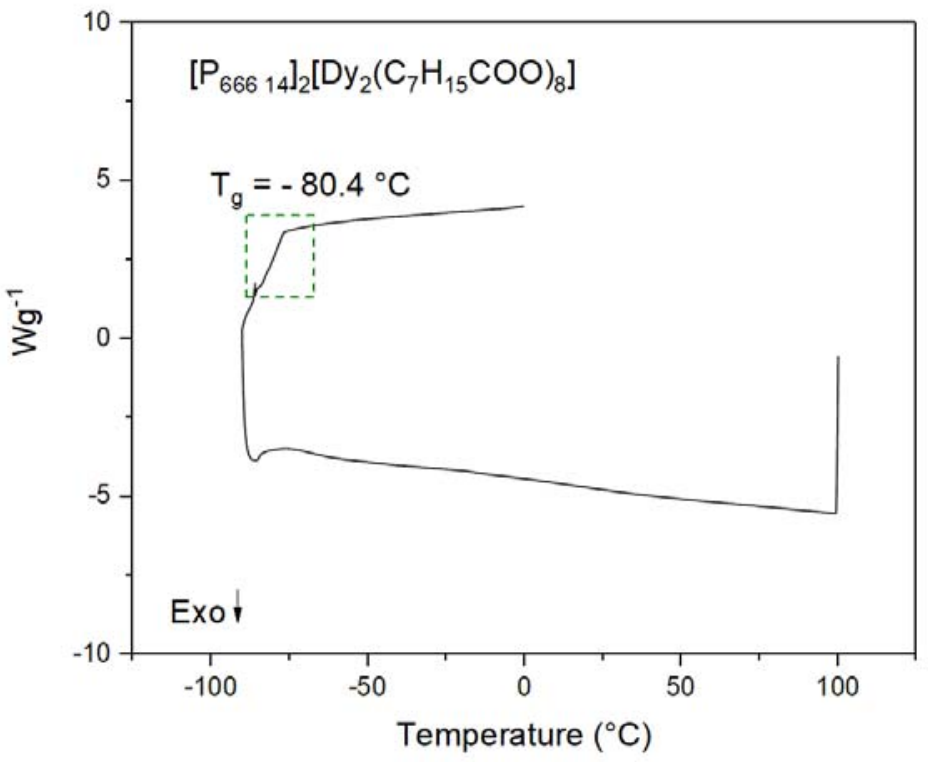

Figure S11. DSC of $\left[\mathrm{P}_{666} 1_{14}\right]_{2}\left[\mathrm{Dy}_{2}\left(\mathrm{C}_{7} \mathrm{H}_{15} \mathrm{COO}\right)_{8}\right]$. 
Table S1. Melting points, crystallisation temperatures, glass transitions and decomposition temperatures of the crystalline, glassy and liquid series.

\begin{tabular}{|c|c|c|c|}
\hline Ln & Solid $\left({ }^{\circ} \mathrm{C}\right)$ & Glass $\left({ }^{\circ} \mathrm{C}\right)$ & Liquids $\left({ }^{\circ} \mathrm{C}\right)$ \\
\hline La & $267\left(T_{\mathrm{dec}}\right)$ & $-60\left(T_{g}\right), 250\left(T_{d e c}\right)$ & \\
\hline $\mathrm{Ce}$ & & & $328\left(T_{\mathrm{dec}}\right)$ \\
\hline $\mathrm{Nd}$ & $73\left(T_{m}\right) 262\left(T_{d e c}\right)$ & $-78\left(T_{\mathrm{g}}\right), 267\left(\mathrm{~T}_{\mathrm{dec}}\right)$ & $333\left(T_{d e c}\right)$ \\
\hline Sm & $259\left(T_{\text {dec }}\right)$ & $-75\left(T_{g}\right), 244\left(T_{d e c}\right)$ & $341\left(T_{d e c}\right)$ \\
\hline Gd & $260\left(T_{\mathrm{dec}}\right)$ & & $317\left(T_{\mathrm{dec}}\right)$ \\
\hline Dy & $118\left(T_{m}\right), 292\left(T_{\mathrm{dec}}\right)$ & $-41.3\left(T_{g}\right), 335\left(T_{\text {dec }}\right)$ & $-80.40\left(\mathrm{~T}_{\mathrm{g}}\right), 348\left(\mathrm{~T}_{\mathrm{dec}}\right)$ \\
\hline $\mathrm{Er}$ & $261\left(T_{d e c}\right)$ & & $317\left(T_{d e c}\right)$ \\
\hline Y & $261\left(T_{\text {dec }}\right)$ & & $322\left(T_{\text {dec }}\right)$ \\
\hline Lu & & & $-59.38\left(T_{g}\right)$ \\
\hline
\end{tabular}

$T_{m}=$ melting point,$T_{g}=$ glass transition temperature, $T_{\text {dec }}=$ decomposition temperature . 


\subsection{UV/Vis Spectroscopy}

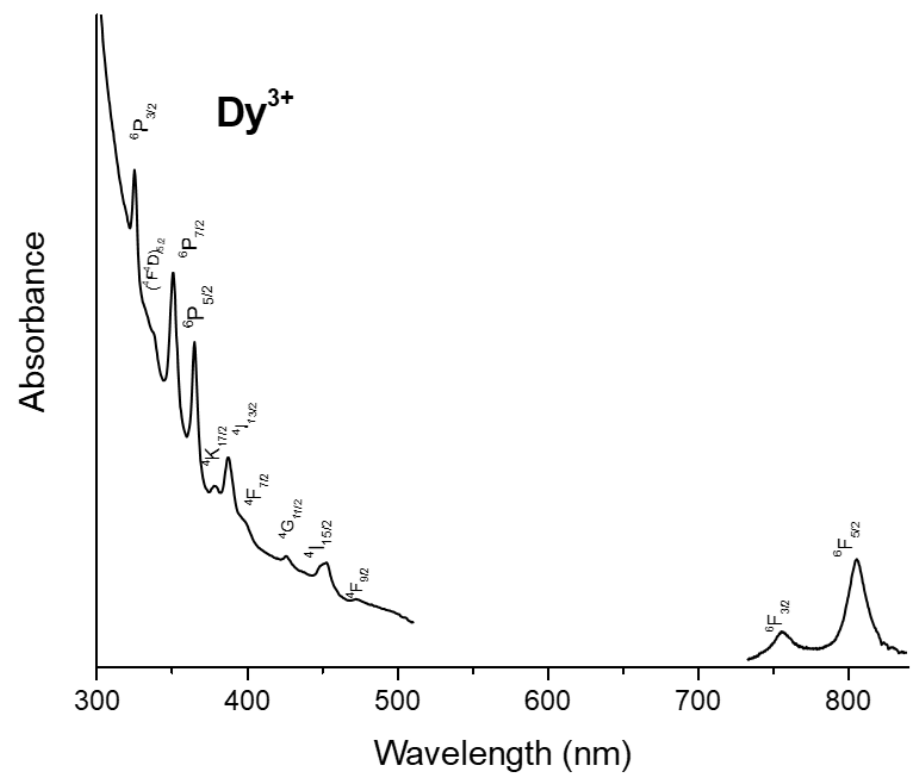

Figure S12. UV/Vis spectrum of $\left[\mathrm{P}_{666} 1_{14}\right]_{2}\left[\mathrm{Dy}_{2}\left(\mathrm{C}_{7} \mathrm{H}_{15} \mathrm{COO}\right)_{8}\right]$

Table S2. Assignment of the $\mathrm{f}-\mathrm{f}$ transitions in $\left[\mathrm{P}_{666}{ }_{14}\right]_{2}\left[\mathrm{Dy}_{2}\left(\mathrm{C}_{7} \mathrm{H}_{15} \mathrm{COO}\right)_{8}\right]$.

\begin{tabular}{cl}
\hline Wavelength $(\mathrm{nm})$ & \multicolumn{1}{c}{ Transition } \\
\hline 325.73 & ${ }^{6} \mathrm{H}_{15 / 2} \rightarrow{ }^{6} \mathrm{P}_{3 / 2}$ \\
338.53 & ${ }^{6} \mathrm{H}_{15 / 2} \rightarrow\left({ }^{4} \mathrm{~F}^{4} \mathrm{D}\right)_{5 / 2}$ \\
351.34 & ${ }^{6} \mathrm{H}_{15 / 2} \rightarrow{ }^{6} \mathrm{P}_{7 / 2}$ \\
365.75 & ${ }^{6} \mathrm{H}_{15 / 2} \rightarrow{ }^{6} \mathrm{P}_{5 / 2}$ \\
380.15 & ${ }^{6} \mathrm{H}_{15 / 2} \rightarrow{ }^{4} \mathrm{~K}_{17 / 2}$ \\
388.15 & $\left.{ }^{6} \mathrm{H}_{15 / 2} \rightarrow{ }^{4}\right|_{13 / 2}$ \\
399.36 & ${ }^{6} \mathrm{H}_{15 / 2} \rightarrow{ }^{4} \mathrm{~F}_{7 / 2}$ \\
426.56 & ${ }^{6} \mathrm{H}_{15 / 2} \rightarrow{ }^{4} \mathrm{G}_{11 / 2}$ \\
452.17 & $\left.{ }^{6} \mathrm{H}_{15 / 2} \rightarrow{ }^{4}\right|_{15 / 2}$ \\
474.58 & ${ }^{6} \mathrm{H}_{15 / 2} \rightarrow{ }^{4} \mathrm{~F}_{9 / 2}$ \\
756.49 & ${ }^{6} \mathrm{H}_{15 / 2} \rightarrow{ }^{6} \mathrm{~F}_{3 / 2}$ \\
807.49 & ${ }^{6} \mathrm{H}_{15 / 2} \rightarrow{ }^{6} \mathrm{~F}_{5 / 2}$ \\
\hline
\end{tabular}




\subsection{Crystallographic Data}

Table S3. Crystal structure data.

\begin{tabular}{|c|c|}
\hline Identification code & {$\left[\mathrm{C}_{4} \mathrm{Mim}\right]_{2}\left[\mathrm{Dy}_{2}\left(\mathrm{CH}_{3} \mathrm{COO}\right)_{8}\right]$} \\
\hline Empirical formula & $\mathrm{C}_{32} \mathrm{H}_{54} \mathrm{~N}_{4} \mathrm{O}_{16} \mathrm{Dy}_{2}$ \\
\hline Formula weight & $1075.79 \mathrm{~g} / \mathrm{mol}$ \\
\hline Temperature/K & $293(2)$ \\
\hline Crystal system & triclinic \\
\hline Space group & $P-1$ \\
\hline $\mathrm{a} / \AA$ & $8.4373(3)$ \\
\hline $\mathrm{b} / \AA \AA$ & $15.5572(4)$ \\
\hline$c / \AA ̊$ & 15.9881(5) \\
\hline$\alpha /^{\circ}$ & $97.705(2)$ \\
\hline$\beta /^{\circ}$ & $103.952(3)$ \\
\hline $\mathrm{Y}^{\circ}$ & $90.338(2)$ \\
\hline Volume $/ \AA^{3}$ & 2016.71(11) \\
\hline Z & 29 \\
\hline$\rho_{\text {calc }} \mathrm{g} / \mathrm{cm}^{3}$ & 4.908 \\
\hline$\mu / \mathrm{mm}^{-1}$ & 141.307 \\
\hline$F(000)$ & 2552.0 \\
\hline \multicolumn{2}{|l|}{ Crystal size $/ \mathrm{mm}^{3}$} \\
\hline Radiation & $\operatorname{CuKa}(\lambda=1.54184)$ \\
\hline $2 \Theta$ range for data collection ${ }^{\circ}$ & 10.814 to 177.41 \\
\hline Index ranges & $-10 \leq h \leq 10,-19 \leq k \leq 19,-18 \leq \mathrm{I} \leq 20$ \\
\hline Reflections collected & 31451 \\
\hline Independent reflections & $7713\left[R_{\text {int }}=0.0688, R_{\text {sigma }}=0.0581\right]$ \\
\hline Data/restraints/parameters & $7713 / 0 / 499$ \\
\hline Goodness-of-fit on $\mathrm{F}^{2}$ & 1.089 \\
\hline Final $R$ indexes $[\mid>=2 \sigma(I)]$ & $\mathrm{R}_{1}=0.0476, w \mathrm{R}_{2}=0.1365$ \\
\hline Final R indexes [all data] & $\mathrm{R}_{1}=0.0557, w \mathrm{R}_{2}=0.1503$ \\
\hline Largest diff. peak/hole / e $\AA^{-3}$ & $1.21 /-2.25$ \\
\hline
\end{tabular}




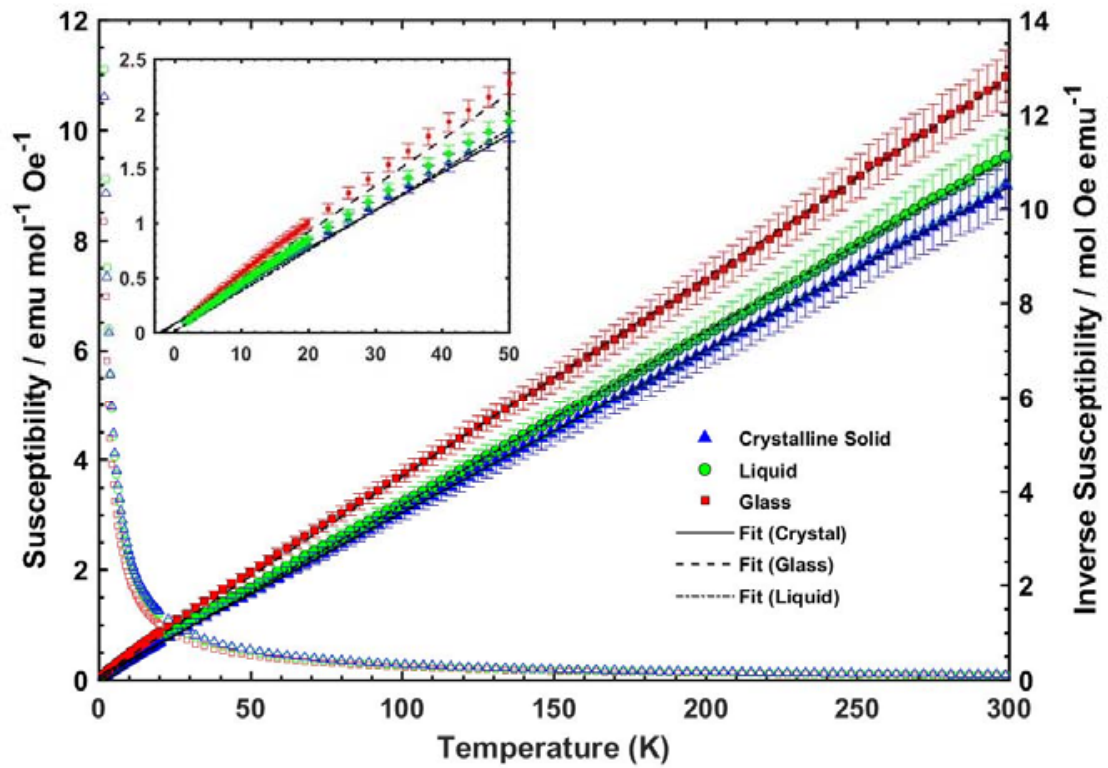

Figure S13. Susceptibility and Inverse susceptibility as a function of temperature. Inset shows low temperature region of the inverse susceptibility in more detail.

The results obtained from fitting the inverse susceptibilities, as shown in Figure S13, using the Curie-Weiss law are summarized in Table S4. The Curie-Weiss law does not take any interactions or zero field splitting into account and therefore must be viewed cautiously. To avoid perturbing the obtained results, the fitting range was limited to $50-300 \mathrm{~K}$, fitting to the low T region using the Curie-Weiss law is nonsensical as the compounds are not behaving as simple paramagnets below this temperature. Even at temperatures higher than $50 \mathrm{~K}$ one would expect the Stark levels to begin depopulating. However, all the extracted ordering temperatures $(\theta)$ are small and negative, implying deviation from paramagnetism at low $\mathrm{T}$, this can be attributed to a range of effects as described in the main text, one of which may be antiferromagnetism.

Equation 1 presents the Curie-Weiss law that was used to fit to the inverse susceptibilities in the temperature range 50 to $300 \mathrm{~K}$ for all the compounds, the fitting was carried out using a linear least squares method and the fits were also weighted to account for the variation in error as a function of temperature.

$\chi=\frac{C}{T-\theta}, \quad$ Equation 1 
SUPPORTING INFORMATION

Table S4 - Curie-Weiss fit results.

\begin{tabular}{cccc}
\hline Phase & Fitting Range $(\mathrm{K})$ & $\begin{array}{c}\theta(\mathrm{K})-\text { Ordering } \\
\text { Temperature }\end{array}$ & $\begin{array}{c}\text { Effective Moment Per Dy lon } \\
\text { (Bohr Magnetons) }\end{array}$ \\
\hline Solid Crystal & $50-300$ & -2.1 & 10.7 \\
Liquid & $50-300$ & -0.2 & 10.4 \\
Glass & $50-300$ & -1.6 & 9.7 \\
\hline
\end{tabular}
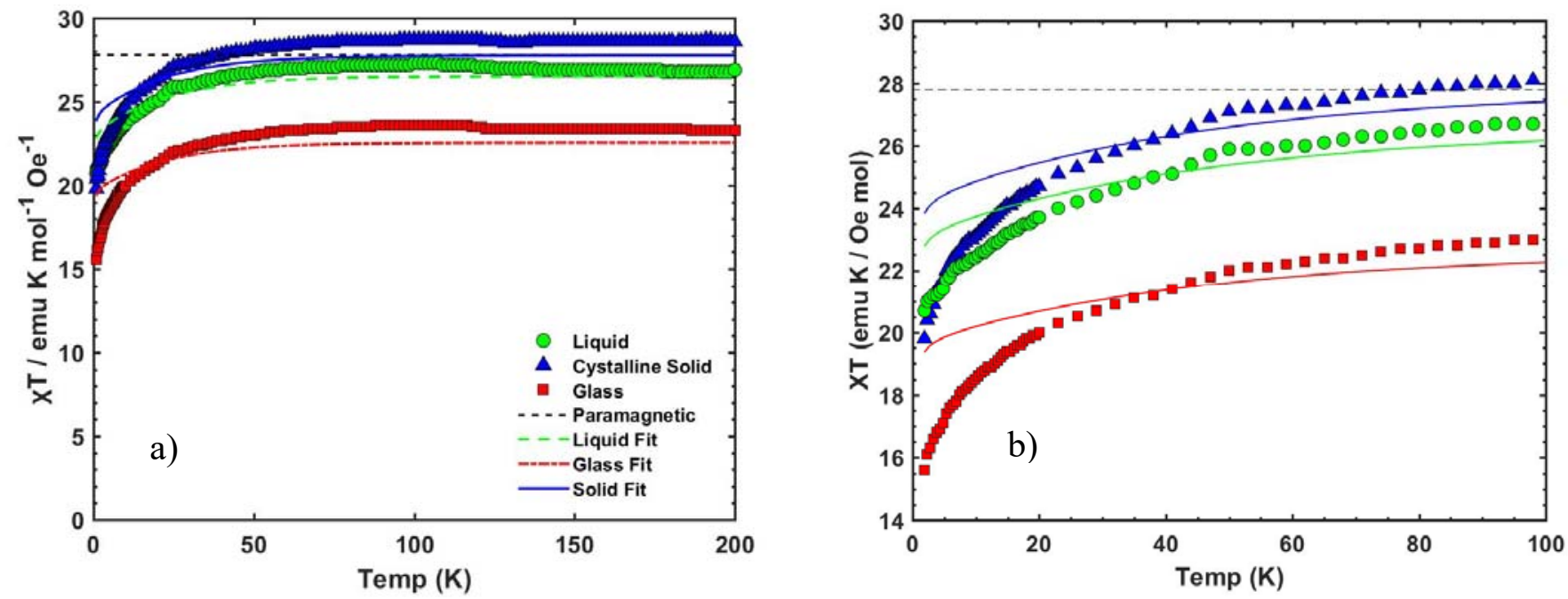

Figure S14. Susceptibility multiplied by temperature, as a function of temperature. Fit only including zero field interactions. Image b) shows the low temperature region of image a) in greater detail.

The glassy sample returned an effective magnetic moment of $9.7 \mu_{\mathrm{B}}$ per Dy ${ }^{\prime \prime I}$ ion. This is $5 \%$ lower than the expected value; however, given that the measurement uncertainty is $5 \%$, these values agree within uncertainty.

\section{References}

[1] G. A. Bain, J. F. Berry, J. Chem. Educ. 2008, 85, 532.

[2] Y. Zhou, J. Dyck, T. W. Graham, H. Luo, D. N. Leonard, J. Qu, Langmuir 2014, 30, 13301-13311.

[3] K. Binnemans, L. Jongen, C. Görller-Walrand, W. D'Olieslager, D. Hinz, G. Meyer, Eur. J. Inorg. Chem. 2000, 2000, 1429-1436.

\section{Author Contributions}

Éadaoin McCourt and Li Zhenyu carried out the experimental procedures and characterization of samples. Dr Kane Esien (KE) performed the SQUID magnetometery and data analysis of magnetic data. Dr Solveig Felton 
WILEY-VCH SUPPORTING INFORMATION

(SF) and Dr Peter Nockemann conceived and supervised the study. All authors contributed to the reading and writing of the manuscript. 